\title{
Effect of Process Parameters on Defects, Melt Pool Shape, Microstructure, and Tensile Behavior of 316L Stainless Steel Produced by Selective Laser Melting
}

\author{
Hua-Zhen Jiang ${ }^{1,2} \cdot{\text { Zheng-Yang } \mathrm{Li}^{2} \cdot \text { Tao Feng }^{3} \cdot \text { Peng-Yue } \mathrm{Wu}^{3} \cdot \text { Qi-Sheng Chen }}^{1,2} \cdot$ Yun-Long Feng ${ }^{3} \cdot$ \\ Long-Fei Chen ${ }^{3} \cdot$ Jing-Yu Hou ${ }^{1,2} \cdot \mathrm{He}-J i a n \mathrm{Xu}^{2}$
}

Received: 25 February 2020 / Revised: 2 August 2020 / Accepted: 3 August 2020 / Published online: 13 October 2020

(c) The Chinese Society for Metals (CSM) and Springer-Verlag GmbH Germany, part of Springer Nature 2020

\begin{abstract}
Previous studies have revealed that laser power and energy density are significant factors affecting the quality of parts manufactured by selective laser melting (SLM). The normalized equivalent density $E_{0}{ }^{*}$ and dimensionless laser power $q^{*}$, which can be regarded as a progress on the understanding of the corresponding dimensional quantities, are adopted in this study to examine the defects, melt pool shape, and primary dendrite spacing of the SLM-manufactured 316L stainless steel, because it reflects the combined effect of process parameters and material features. It is found that the number of large defects decreases with increasing $E_{0} *$ due to enough heat input during the SLM process, but it will show an increasing trend when excessive heat input (i.e., utilizing a high $E_{0}{ }^{*}$ ) is imported into the powder bed. The $q^{*}$ plays an important role in controlling maximum temperature rising in the SLM process, and in turn, it affects the number of large defects. A large $q^{*}$ value results in a low value of absolute frequency of large defects, whereas a maximum value of absolute frequency of large defects is achieved at a low $q^{*}$ even if $E_{0} *$ is very high. The density of the built parts is greater at a higher $q^{*}$ when $E_{0} *$ remains constant. Increasing the melt pool depth at relatively low value of $E_{0}{ }^{*}$ enhances the relative density of the parts. A narrow, deep melt pool can be easily generated at a high $q^{*}$ when $E_{0}{ }^{*}$ is sufficiently high, but it may increase melt pool instability and cause keyhole defects. It is revealed that a low $E_{0} *$ can lead to a high cooling rate, which results in a refined primary dendrite spacing. Relatively low $E_{0} *$ is emphasized in selecting the process parameters for the tensile test sample fabrication. It shows that excellent tensile properties, namely ultimate tensile strength, yield strength, and elongation to failure of $773 \mathrm{MPa}, 584 \mathrm{MPa}$, and $46 \%$, respectively, can be achieved at a relatively low $E_{0}{ }^{*}$ without heat treatment.
\end{abstract}

Keywords Selective laser melting $\cdot$ Defects $\cdot$ Melt pool shape $\cdot$ Primary dendrite spacing $\cdot$ Mechanical properties $\cdot 316 \mathrm{~L}$ stainless steel

Electronic supplementary material The online version of this article (https://doi.org/10.1007/s40195-020-01143-8) contains supplementary material, which is available to authorized users.

Available online at https://link.springer.com/journal/40195.

Zheng-Yang Li

zyli@imech.ac.cn

$\checkmark$ Qi-Sheng Chen

qschen@imech.ac.cn

1 School of Engineering Science, University of Chinese Academy of Sciences, Beijing 100190, China

2 Institute of Mechanics, Chinese Academy of Sciences, Beijing 100190, China

3 Beijing E-Plus-3D Technology Co., LTD, Beijing 102299, China

\section{Introduction}

Selective laser melting (SLM), as one of the additive manufacturing (AM) methods, has great potential for promoting the design and manufacturing of products in many fields across the vast spectrum of engineering and materials science. It is one of the leading techniques of AM that enables direct computer-aided design of parts without part-specific tooling. However, many obstacles have to be overcome before it can become an industrially viable, widely accepted manufacturing technology. One of these obstacles is understanding the relationship between the process parameters and the resultant properties of parts manufactured by SLM. It has been pointed out that there are more than 130 factors affecting the quality of parts built by AM [1]. In addition, 
numerous investigations have been conducted to reveal the relationships between the process parameters and the properties of parts produced by AM [2-5]. The properties of aluminum alloys or titanium alloys manufactured by AM can be greatly enhanced by adding certain elements to form refined grains $[6,7]$. In contrast, $316 \mathrm{~L}$ stainless steel (316L SS) samples additively manufactured via SLM are reported to exhibit yield strength (YS) and tensile ductility values that considerably surpass those of wrought 316L SS [8-11]. These results indicate the probability of optimizing the SLM process parameters to tailor the microstructures and obtain excellent mechanical properties of manufactured parts by utilizing specific SLM processing strategies. For optimizing the process parameters, the Taguchi methods with orthogonal array design and dimensional analysis would be valuable [12-14]. With the normalized processing map and dimensionless parameters developed by Thomas [15], it is concluded that laser power (corresponding to normalized power $q^{*}$ ) is the most significant factor affecting all the response variables, while the normalized equivalent energy density $\left(E_{0} *\right)$ is also a key processing index for controlling the properties of built parts [15-17].

Thomas et al. [15] have outlined the practical processing limits for several materials processed by powder bed fusion with the normalized process parameters and normalized processing diagram. Regions where either voids or internal cracks are observed are annotated on the normalized processing map. However, an optimum processing window which is applicable to one material by the normalized processing diagram has not been well established. Of particular importance is that there is also little information available on how microstructure varies with $E_{0}{ }^{*}$. In this study, a normalized process map is adopted to design the experiment. The validity of the normalized process map and dimensionless variables has been demonstrated by recent works [10, $16,18,19]$. To explore the process parameters in a more extensive range, parameters are deliberately selected so that the corresponding dimensionless variables plotted on the normalized process map are extended to a larger range than that of the map in Ref. [16]. The relative density of the built part is examined in detail through analyzing the micrograph of a cross section of the part with the aid of quantitative index, namely circularity index (CI) [15]. A high laser power may generate a keyhole effect or an intensive flow, which increases the porosity of the built part. Therefore, low values of normalized equivalent energy density $\left(E_{0}^{*}\right)$ and normalized power $\left(q^{*}\right)$ are emphasized when selecting experimental parameters to avoid such problems and reduce the production cost. Finally, to verify the results of the experiment, tensile tests are carried out with dogbone samples. The results of tensile tests and fracture morphology are then analyzed.

\section{Experimental}

\subsection{Design of Experiment}

Previous studies have shown that the mechanical properties of SLM-manufactured parts are strongly affected by defects [20], melt pool shape [21], and primary dendrite spacing [3, 10], which are dependent on the process parameters. A thorough understanding of the relationship between them is of great importance. The experimental work in this study will focus on the effect of process parameters on the following response variables: internal defects, melt pool shape, and primary dendrite spacing.

The expressions of the normalized quantities are defined in the following [15].

Dimensionless laser power is

$q^{*}=A q /\left[R \lambda\left(T_{\mathrm{m}}-T_{0}\right)\right]$,

where $A$ is the surface absorptivity, $q$ the laser power (W), $R$ the laser beam radius $(\mathrm{m}), \lambda$ the thermal conductivity ( $\mathrm{W} \mathrm{m}^{-1} \mathrm{~K}^{-1}$ ), $T_{\mathrm{m}}$ the melting temperature $(\mathrm{K})$, and $T_{0}$ the initial (or powder bed) temperature of the material $(\mathrm{K})$. Dimensionless laser scanning speed is

$v^{*}=\nu R / \alpha$,

where $v$ is the laser scanning speed $\left(\mathrm{m} \mathrm{s}^{-1}\right)$ and $\alpha$ is the thermal diffusivity at melting point $\left(\mathrm{m}^{2} \mathrm{~s}^{-1}\right)$. The dimensionless layer height $\left(l^{*}\right)$ and dimensionless hatch spacing $\left(h^{*}\right)$ are defined as

$l^{*}=2 l / R, \quad h^{*}=h / R$,

where $l$ and $h$ are the layer thickness $(\mu \mathrm{m})$ and hatch spacing $(\mu \mathrm{m})$, respectively.

The dimensionless normalized equivalent energy density $E_{0} *$ is defined as

$E_{0}^{*}=q^{*} /\left(v^{*} l^{*} h^{*}\right)=[A q / 2 v l h]\left[1 / \rho C_{\mathrm{p}}\left(T_{\mathrm{m}}-T_{0}\right)\right]$,

where $\rho$ is the density of $316 \mathrm{~L} \mathrm{SS}\left(\mathrm{kg} \cdot \mathrm{m}^{-3}\right)$ and $C_{\mathrm{p}}$ is the specific heat capacity $\left(\mathrm{J} \mathrm{kg}^{-1} \mathrm{~K}^{-1}\right)$. According to Ion et al. [14] and Thomas et al. [15], $q^{*}$ and $v^{*}$ can be used to control the peak temperature and heating rate of the thermal cycle at a point in the material, while $E_{0} *$ represents the ratio of the dimensionless volumetric heat input per scan line to the dimensionless hatch spacing. Physically, a constant $E_{0}$ * value provides an equally energy efficient treatment during SLM [15]. To better understand the variation of internal defects, melt pool shape, and microstructure with the process parameters, the parameters are selected based on the following principles: 
1. Three levels of laser power, i.e., $95 \mathrm{~W}, 206 \mathrm{~W}$, and $360 \mathrm{~W}$, which correspond to low power (L-P), medium power (M-P), and high power (H-P), respectively, are utilized.

2. If $E_{0} *$ remains constant during the SLM process at the three different laser power levels, then values of $q^{*} / v^{*}$, normalized hatch spacing $h^{*}$, and normalized layer thickness $l^{*}$ are kept constant.

3. At a certain laser power, the dimensionless hatch spacing $h^{*}$ or dimensionless scanning speed $v^{*}$ is changed, resulting in $E_{0}{ }^{*}$ values within the range of 1.49-5.25.

During the SLM process, the layer thickness ( $l$ ) remains unchanged $(30 \mu \mathrm{m})$, which corresponds to a normalized layer thickness $\left(l^{*}\right)$ of 1.5 . The various designed process parameters are listed in Table 1 (the rightmost column is the experiment result of relative density). The thermophysical properties of 316L SS used for calculating the normalized quantities are presented in Table 2. To compare our experimental data with those of other studies, the dimensionless quantities calculated from Table 1 are plotted in Fig. 1 together with the normalized data from other studies. It can be observed that the minimum energy density (corresponding to $E_{0} *=1.49$ ) in this study is close to that of the pulse mode laser condition, while the maximum energy density (corresponding to $E_{0} *=5.25$ ) exceeds the data from most of the other studies.

Figure 2 shows the scanning electron microscopy (SEM) image of the 316L SS powder used in the study. It is a gas atomized spherical powder supplied by Avimetal Powder

Table 1 List of processing parameters in this study

\begin{tabular}{|c|c|c|c|c|c|c|c|c|c|}
\hline \multirow[t]{2}{*}{ Sample No. } & \multicolumn{6}{|c|}{ Process parameters } & \multirow{2}{*}{$\begin{array}{l}\text { Volume } \\
\text { energy density } \\
E\left(\mathrm{~J} / \mathrm{mm}^{3}\right)\end{array}$} & \multirow{2}{*}{$\begin{array}{l}\text { Normalized equiva- } \\
\text { lent energy density } \\
E_{0} *\end{array}$} & \multirow{2}{*}{$\begin{array}{l}\text { Experimental } \\
\text { results of relative } \\
\text { density } \\
\rho_{0}(\%)\end{array}$} \\
\hline & $q(\mathrm{~W})$ & $q^{*}$ & $v(\mathrm{~mm} / \mathrm{s})$ & $v^{*}$ & $h(\mu \mathrm{m})$ & $h^{*}$ & & & \\
\hline \multicolumn{10}{|l|}{ Low power } \\
\hline 1 & 95 & 20.99 & 415 & 3.09 & 50 & 1.25 & 152.61 & 4.21 & $97.70 \pm 0.97$ \\
\hline 2 & 95 & 20.99 & 415 & 3.09 & 70 & 1.75 & 109.01 & 3.00 & $96.78 \pm 1.03$ \\
\hline 3 & 95 & 20.99 & 415 & 3.09 & 90 & 2.25 & 84.78 & 2.34 & $97.71 \pm 1.09$ \\
\hline 4 & 95 & 20.99 & 415 & 3.09 & 110 & 2.75 & 69.37 & 1.91 & $98.49 \pm 0.32$ \\
\hline 5 & 95 & 20.99 & 415 & 3.09 & 130 & 3.25 & 58.70 & 1.62 & $97.69 \pm 0.43$ \\
\hline 6 & 95 & 20.99 & 650 & 4.83 & 90 & 2.25 & 54.13 & 1.49 & $98.14 \pm 0.62$ \\
\hline 7 & 95 & 20.99 & 530 & 3.94 & 90 & 2.25 & 66.39 & 1.83 & $97.97 \pm 0.58$ \\
\hline 8 & 95 & 20.99 & 300 & 2.23 & 90 & 2.25 & 117.28 & 3.23 & $97.72 \pm 0.84$ \\
\hline 9 & 95 & 20.99 & 185 & 1.38 & 90 & 2.25 & 190.19 & 5.24 & $95.95 \pm 0.80$ \\
\hline \multicolumn{10}{|c|}{ Medium power } \\
\hline 10 & 206 & 45.52 & 900 & 6.69 & 50 & 1.25 & 152.59 & 4.21 & $98.17 \pm 0.97$ \\
\hline 11 & 206 & 45.52 & 900 & 6.69 & 70 & 1.75 & 108.99 & 3.00 & $96.95 \pm 1.19$ \\
\hline 12 & 206 & 45.52 & 900 & 6.69 & 90 & 2.25 & 84.77 & 2.33 & $98.93 \pm 0.49$ \\
\hline 13 & 206 & 45.52 & 900 & 6.69 & 110 & 2.75 & 69.36 & 1.91 & $98.97 \pm 0.35$ \\
\hline 14 & 206 & 45.52 & 900 & 6.69 & 130 & 3.25 & 58.70 & 1.62 & $97.57 \pm 0.87$ \\
\hline 15 & 206 & 45.52 & 1400 & 10.41 & 90 & 2.25 & 54.50 & 1.50 & $98.66 \pm 0.43$ \\
\hline 16 & 206 & 45.52 & 1150 & 8.55 & 90 & 2.25 & 66.34 & 1.83 & $97.69 \pm 0.57$ \\
\hline 17 & 206 & 45.52 & 650 & 4.83 & 90 & 2.25 & 117.38 & 3.24 & $96.83 \pm 0.86$ \\
\hline 18 & 206 & 45.52 & 400 & 2.97 & 90 & 2.25 & 190.74 & 5.26 & $97.37 \pm 1.55$ \\
\hline \multicolumn{10}{|l|}{ High power } \\
\hline 19 & 360 & 79.54 & 1575 & 11.71 & 50 & 1.25 & 152.38 & 4.20 & - \\
\hline 20 & 360 & 79.54 & 1575 & 11.71 & 70 & 1.75 & 108.84 & 3.00 & - \\
\hline 21 & 360 & 79.54 & 1575 & 11.71 & 90 & 2.25 & 84.66 & 2.33 & $99.22 \pm 0.31$ \\
\hline 22 & 360 & 79.54 & 1575 & 11.71 & 110 & 2.75 & 69.26 & 1.91 & $98.14 \pm 0.88$ \\
\hline 23 & 360 & 79.54 & 1575 & 11.71 & 130 & 3.25 & 58.61 & 1.62 & $98.36 \pm 0.28$ \\
\hline 24 & 360 & 79.54 & 2465 & 18.33 & 90 & 2.25 & 54.09 & 1.49 & $98.60 \pm 0.23$ \\
\hline 25 & 360 & 79.54 & 2010 & 14.94 & 90 & 2.25 & 66.33 & 1.83 & $99.17 \pm 0.15$ \\
\hline 26 & 360 & 79.54 & 1135 & 8.44 & 90 & 2.25 & 117.47 & 3.24 & $98.50 \pm 0.40$ \\
\hline 27 & 360 & 79.54 & 700 & 5.20 & 90 & 2.25 & 190.48 & 5.25 & $97.96 \pm 0.83$ \\
\hline
\end{tabular}


Table 2 Thermophysical properties of 316L SS used for calculating the normalized quantities

\begin{tabular}{llllllll}
\hline $\mathrm{A} \mathrm{[22]}$ & $\lambda\left(\mathrm{W} \mathrm{m}^{-1} \mathrm{~K}^{-1}\right)[23]$ & $\alpha\left(\mathrm{m}^{2} \mathrm{~s}^{-1}\right)[24]$ & $\rho\left(\mathrm{kg} \mathrm{m}^{-3}\right)[25]$ & $C_{\mathrm{p}}\left(\mathrm{J} \mathrm{kg}^{-1} \mathrm{~K}^{-1}\right)[23]$ & $T_{\mathrm{m}}(\mathrm{K})$ & $T_{0}(\mathrm{~K})$ \\
\hline 0.35 & 29.55 & $5.38 \times 10^{-6}$ & 7980 & 592.24 & 1673 & 333 \\
\hline
\end{tabular}

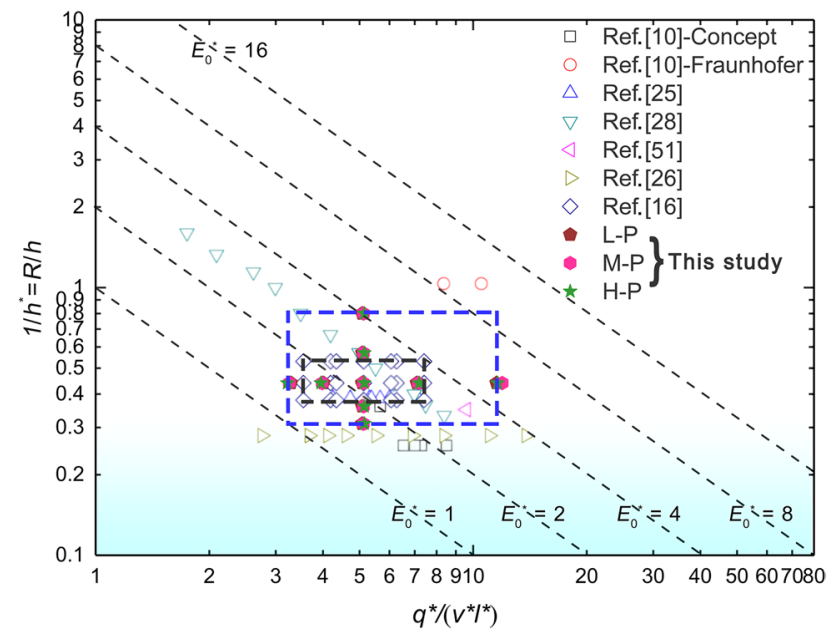

Fig. 1 Normalized process map showing the location of dimensional variables corresponding to the experimental process parameters selected from Table 1 (the experimental data are enclosed in the blue dashed rectangle and the boundary of the experimental data in Ref. [16] is the black dashed rectangle). Contours of constant normalized equivalent energy density, $E_{0}{ }^{*}$, are provided by the dashed lines

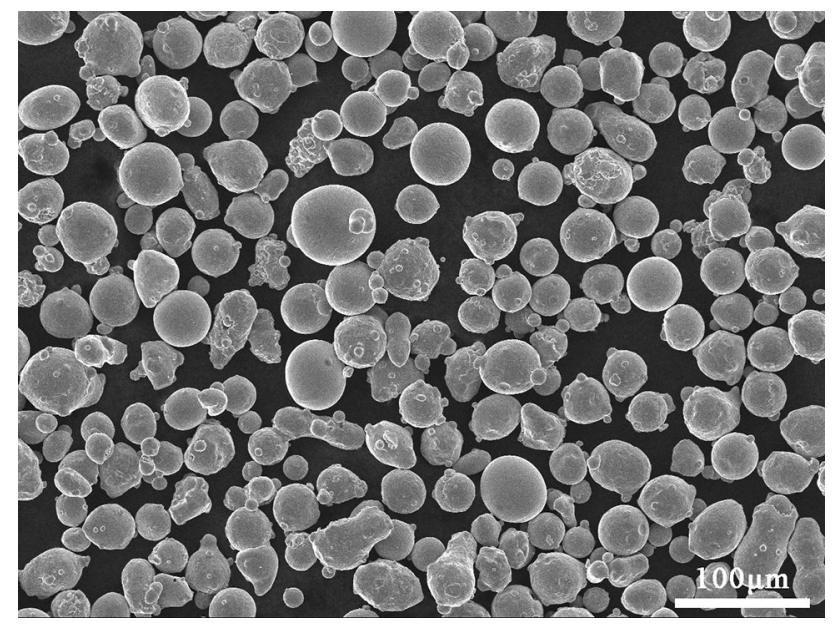

Fig. 2 SEM image of the 316L SS powder used

Metallurgy Technology Co., Ltd, China, with a particle size distribution of $15-53 \mu \mathrm{m}$. The nominal chemical composition by weight is $18.84 \% \mathrm{Cr}, 10.68 \% \mathrm{Ni}, 2.26 \% \mathrm{Mo}, 1.05 \%$ $\mathrm{Mn}, 0.91 \% \mathrm{Si},<0.03 \% \mathrm{C},<0.04 \% \mathrm{P},<0.01 \% \mathrm{~S},<0.1 \% \mathrm{~N}$, and the balance $\mathrm{Fe}$. The experiment was conducted using EP-M250 (Shining 3D, China), which is a commercial product mainly consisting of a fiber laser with a maximum power

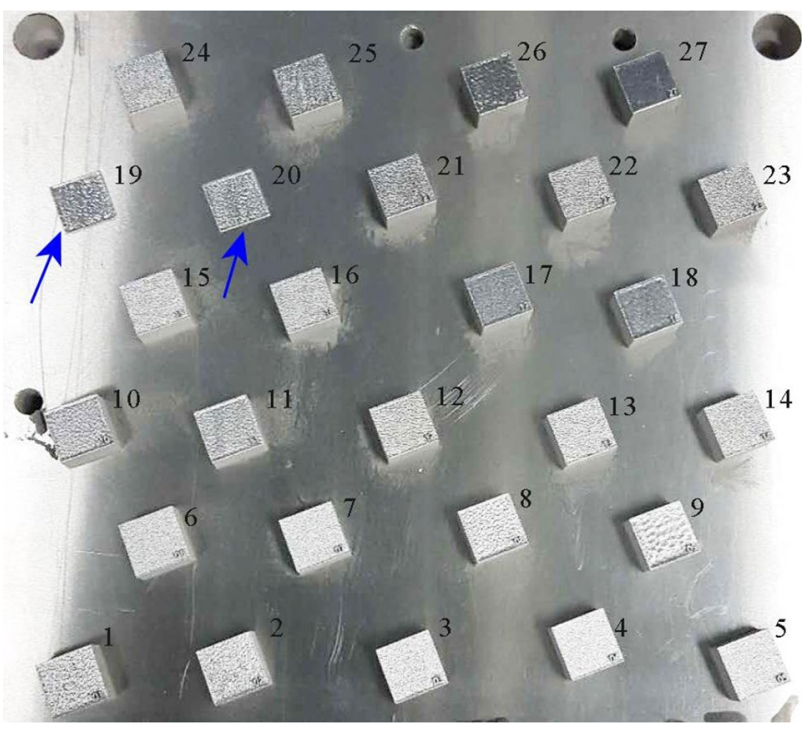

Fig. 3 Layout of cube array (the blue arrows indicate that the part cannot be successfully fabricated under this process parameter)

of $400 \mathrm{~W}$ and a beam diameter of $80 \mu \mathrm{m}$, an independently developed slicing software "E-plus 3D printing system," an automatic powder feeding system, an inner gas protection system, and a computer system for controlling the process. The oxygen content was maintained below $\sim 1000$ ppm during the SLM process. A zigzag, also often referred to as the meander scan strategy, was used for each component, where the angle of the laser was rotated by $67^{\circ}$ between each layer. Twenty seven parts under the different process parameters listed in Table 1 were fabricated (Fig. 3). Each part measures $15 \mathrm{~mm}$ (length) $\times 15 \mathrm{~mm}$ (width) $\times 10 \mathrm{~mm}$ (height) with the height of $10 \mathrm{~mm}$ along the build direction (Fig. 4a).

\subsection{Analysis of Microstructural Characteristics}

Each part was cut from the substrate by wire cutting. The side faces of all samples were ground using $\mathrm{SiC}$ papers from 200-3000 grits before being polished using a $1.5-\mu \mathrm{m}$ diamond suspension. To better understand the information about the size, distribution, and form of defect in the asfabricated part, an image analysis method was adopted in the experiment instead of the Archimedes principle to evaluate the relative density $[15,26]$. The density measurement using the above two methods seems to be contrary to each other. Some authors reported that the measured density is higher when using the image analysis method [25, 27]. Others 

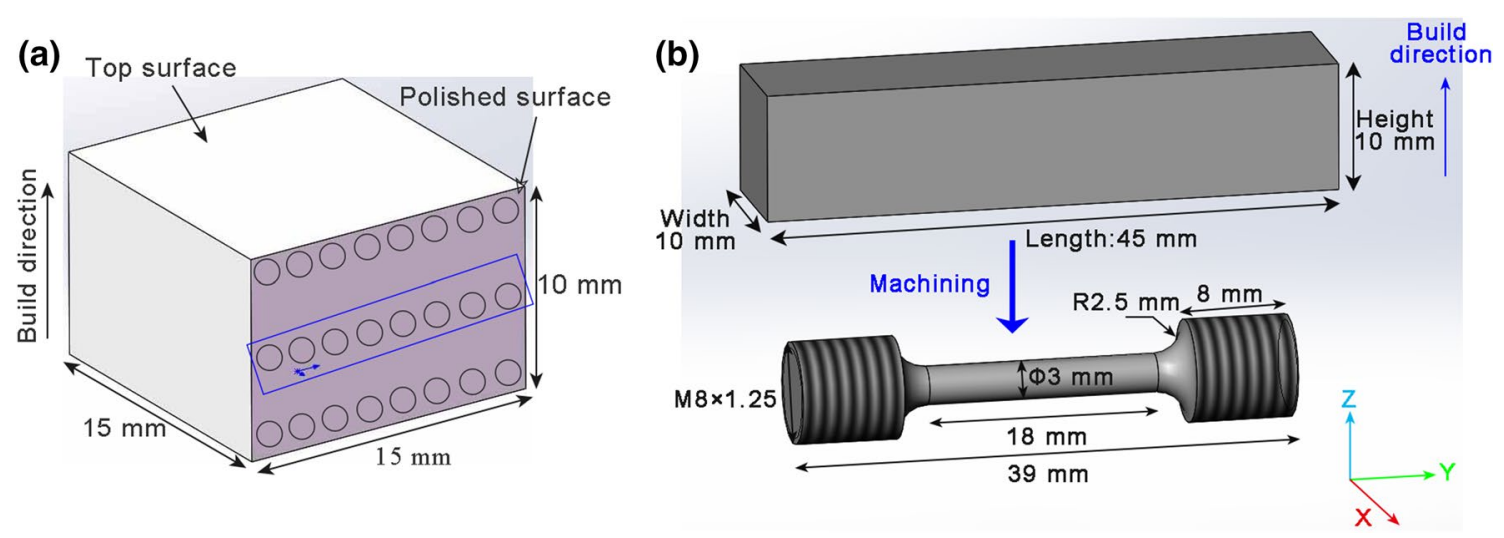

Fig. 4 Dimension of the as-fabricated sample and as-fabricated tensile specimen: a sketch of the 24 regions of interest for evaluating the density of each part, among which 8 regions of interest for quantitative statistics of defect size and morphology are indicated by the blue rectangle; $\mathbf{b}$ dimension of the dogbone sample after machining

argued that using the Archimedes method might overestimate the relative density because the unmelted powder particles could be filled in the pores, which will also contribute to the total mass of the sample, and therefore increase the measured density $[28,29]$. These contradictory results can be attributed to the different detected cross sections, different magnifications, and different selected positions taken for the micrographs, which can affect the measured density [26]. The density measurement should be based on several micrographs allowing to calculate a mean value within a certain cross section, especially at relatively higher magnifications, e.g., $80 \times$ [26]. The relative density $\rho_{0}$ of each part (in percentage) was analyzed using the Image-Pro Plus 6.0 software under optical microscopy (OM) (55XA, Shanghai Optical Instrument Factory). The porosity, which is equal to $100 \%$ minus $\rho_{0}$, is evaluated by calculating the area percentage of pores on the polished surface. The population of pores was measured by examining up to 24 regions per specimen from 3 lines of 8 regions; the lines are located at the top, middle, and bottom of the part (Fig. $4 \mathrm{a}$; the regions of interest are represented by a circle). Since the outermost materials were removed from the SLM-processed parts before tensile tests, only eight OM images of the middle part were quantified statistically to qualify the size and morphology of pores (Fig. 4a; the blue rectangle shows the eight observed regions). The absolute frequency is used to count the number of defects presented within the observed range. CI is used to indicate the roundness of the defects and is calculated by using the following equation [15]:

$\mathrm{CI}=\left(4 \pi A_{\mathrm{F}}\right) /\left(P_{\mathrm{F}}^{2}\right)$,

where $A_{\mathrm{F}}$ is the cross-sectional area of a given microstructural feature and $P_{\mathrm{F}}$ is the perimeter. $\mathrm{CI}=1$ means a perfectly spherical pore. After porosity counting, all the samples were chemically etched in an acidic water solution containing $2 \%$
$\mathrm{HF}$ and $8 \% \mathrm{HNO}_{3}$ for approximately $30 \mathrm{~min}$ at room temperature. Cross-sectional examinations of the scanning tracks parallel to the build direction were carried out by $\mathrm{OM}$ and SEM (FEI Sirion $400 \mathrm{NC}, 15 \mathrm{kV}$ ) to observe the defects and melt pool shape. The quantitative index, namely primary dendrite spacing $\lambda_{0}$, was measured using at least three SEM images in arbitrary regions at each sample.

\subsection{Test of Mechanical Properties}

To verify the results of the microstructural characteristic analysis of the as-fabricated parts, tensile tests were performed with parameters corresponding to the better analysis results, while a low $E_{0} *$ value was emphasized. Rectangular bars with dimensions of $45 \mathrm{~mm}$ (length) $\times 10 \mathrm{~mm}$ (width) $\times 10 \mathrm{~mm}$ (height) were produced with the height parallel to the build direction (Fig. 4b). The meander scan strategy was used for the fabrication of the rectangular bars with the angle of the laser rotated by $67^{\circ}$ between each layer. During the SLM process, the oxygen content was also maintained below $\sim 1000 \mathrm{ppm}$. The fabricated rectangular bars were machined to standard dogbone samples according to GB/T 228.1-2010 (Fig. 4b). Tensile tests were carried out at room temperature on a CMT5105S testing machine (SANS, China) at a crosshead velocity of $2 \mathrm{~mm} / \mathrm{min}$. The tensile direction was parallel to the length direction (Fig. 4b). The mechanical properties were the average results of five tests with the same process parameters. After tensile testing, the fracture surfaces of the tensile specimens were observed by SEM. 


\section{Results and Discussion}

\subsection{Effect of Process Parameters on Relative Density, Defects, and Melt Pool Shape}

\subsubsection{Relative Density}

Figure 3 shows that sample No. 19 and No. 20 cannot be successfully fabricated as indicated by the blue arrows. Two reasons might be responsible for the outcome of the failure for No. 19 and No. 20 SLM-produced parts. On the one hand, the scanning speed used in the two samples is $1575 \mathrm{~mm} / \mathrm{s}$ which is greater than that of the other samples except Sample No. 24 and No. 25. Such a high scanning speed results in a large amount of micrometer-scaled balls on the SLMed surface [30]. On the other hand, the hatch spacing utilized by Sample No. 19 and No. 20 is $50 \mu \mathrm{m}$ and $70 \mu \mathrm{m}$, respectively, which is less than that of the other samples. The hatch spacing used for a combination of a certain process parameter might beyond the optimum processing window for forming good surface. In fact, by gradually increasing the hatch spacing, the SLM-manufactured parts could be fabricated successfully (Table 1, Sample Nos. 19-23). The large amount of micrometer-scaled balls and overlapped scanning tracks caused by utilizing a high scanning speed and a low hatch spacing in Sample No. 19 and No. 20, respectively, could deteriorate the surface flatness, thereby hindering the paving process. The density measurement result is shown in Fig. 5a which is derived from image analysis by the rest of 25 samples.

(a)

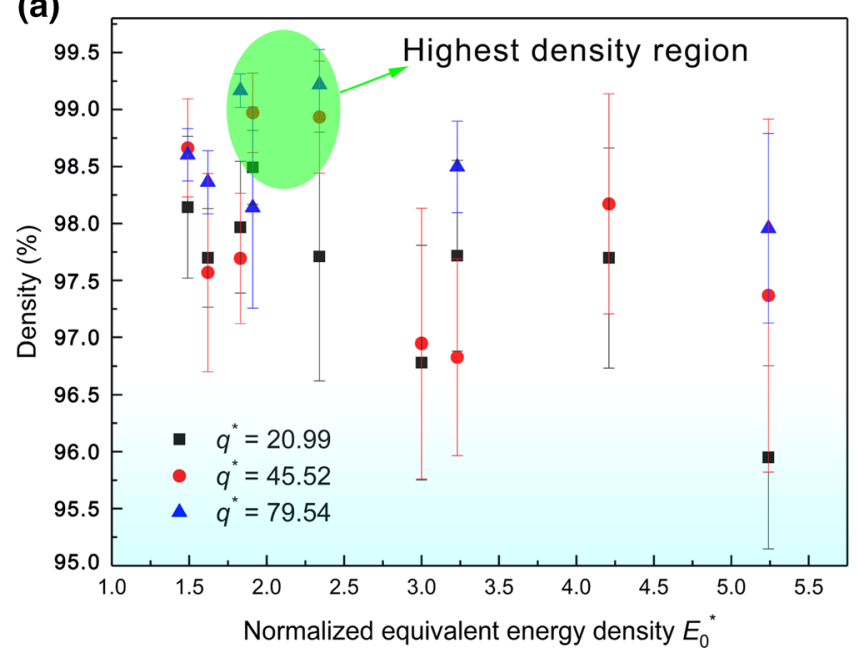

Though the data scatter is large, the highest density region at different normalized laser powers can still be clearly observed in Fig. 5a (the highest density region at the three $q^{*}$ values are marked by green ellipse). Beyond this region, the relative density would show a lower value. The variation of porosity accordingly to different process parameters is illustrated in "Electronic supplementary material," where the high-density region is highlighted by a blue dashed rectangle. The top four highest densities presented in Fig. 5a are 99.22\%, 99.17\%, 98.97\%, and 98.93\%, which correspond to those of Sample No. 21, No. 25, No. 13, and No. 12, respectively (see Table 1$)$. The relative density tends to decline quickly at L-P $\left(q^{*}=20.99\right)$, while it remains greater than $98 \%$ at $\mathrm{H}-\mathrm{P}\left(q^{*}=79.54\right)$ even when the process parameters vary extensively. This phenomenon was also observed by Kamath et al. [25], who reported that higher power values can provide greater flexibility in choosing the process parameters that can optimize the various properties of a manufactured part. The density of the part at $\mathrm{H}-\mathrm{P}$ is generally greater than those at L-P and M-P when $E_{0}{ }^{*}$ is constant. It can be roughly concluded that the highest density range is associated with $E_{0} *$ and $q^{*}$ values of approximately $1.83-2.33$ and $45.52-79.54$, respectively. According to Wang et al. [31] and Thomas et al. [15], the normalized processing diagram can be used to identify processing window for different materials and offer a better comparison with various laser process parameters from different SLM machines. Here, we compare our results (i.e., the top four highest densities) with the work carried out by others, including data from several studies on $\mathrm{Ti}-6 \mathrm{Al}-4 \mathrm{~V}$ and 316L SS processed by different SLM machines (as shown in Fig. 5b). It is observed that high-density samples can be

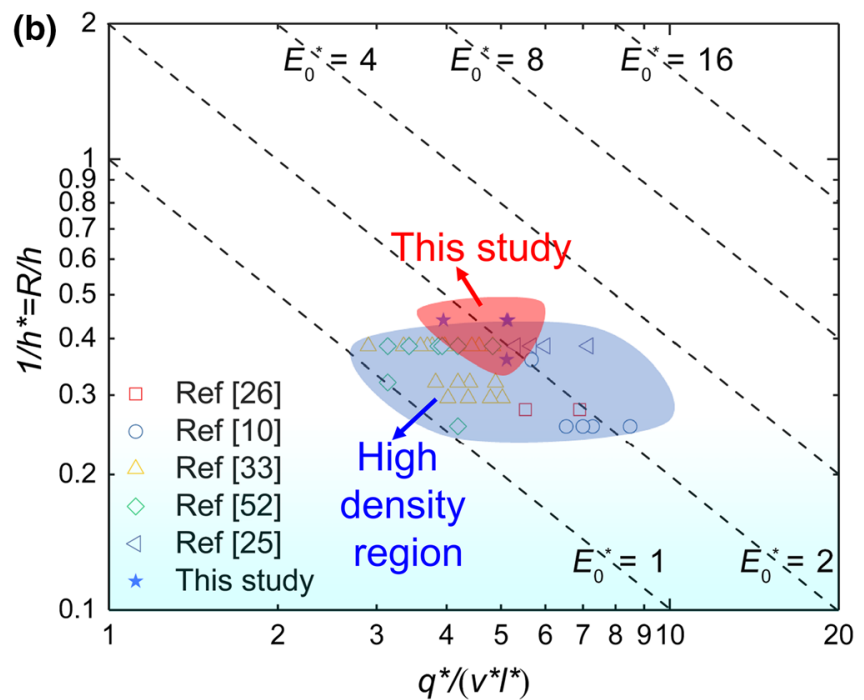

Fig. 5 Effect of process parameters on relative density: a density measurement results, $\mathbf{b}$ a normalized processing diagram showing the location of high-density (>99\%) SLM-processed part. The dashed lines represent contours of constant $E_{0} *$ 
produced in a region when $1.1<E_{0} *<2.5$, regardless of the materials and machine type. It is worthy of noticing that the highest density attained in this study lies in this region, suggesting that the normalized processing diagram might be a good indicator for SLM process. It should be emphasized that scan strategy and powder layer characteristics are not considered in such a processing diagram although they are expected to impact the density of parts [31].

Actually, the data scatter (i.e., the length of "error bar") at a certain process parameter is relatively large because both the dimension and number of pores differ greatly from image to image (see Electronic supplementary material). It is found that the amount of pores near the top of the sample is greater than those in the middle and the bottom because the as-fabricated samples in the bottom occupied a higher temperature region, where the substrate was preheated and experienced more thermal cycles that facilitated more complete melting of powder than those at the middle and the top.

Another way of distinguishing the density of SLMproduced parts under the different process parameters is to observe melt flow traces on the top surface structure of the as-fabricated samples [32]. Figure 6 displays a typical surface structure of samples under various $E_{0} *$ and $q^{*}$ values. Although a constant $E_{0} *$ value suggests an equally energy efficient process, the surface structure at $E_{0} *=5.25$ is very different. It is irregularly shaped at L-P (Fig. 6a) due to serious balling. It is prone to be smoother and homogeneously overlapped with neighboring scanning tracks at relatively higher laser power values, i.e., M-P and H-P (Fig. 6b, c). Figure 6c-f indicates that the top surface structure tends to become flatter with $E_{0} *$ increasing from 1.49 to 5.25 when $q^{*}$ is kept at a higher value of 79.54 . This implies that a greater value of $E_{0} *$ may lead to a lower surface roughness, which is consistent with the results of the studies by Jiang et al. [16] and Cherry et al. [33]. The top surface structure will develop cave-like pores because the next layer overhangs the previous layer if $E_{0} *$ is extremely low. It can be seen from Table 1 that the scanning speed is up to $2465 \mathrm{~mm} / \mathrm{s}$, corresponding to $v^{*}=18.33$ for Sample No. 24. The melt pool may become unstable in this case due to more pronounced splashing of molten particles [32]. It is noted that the lowest $E_{0} *$ value does not result in the lowest relative density, although the top surface structure at $E_{0} *=1.49$ is significantly more irregular than that at the
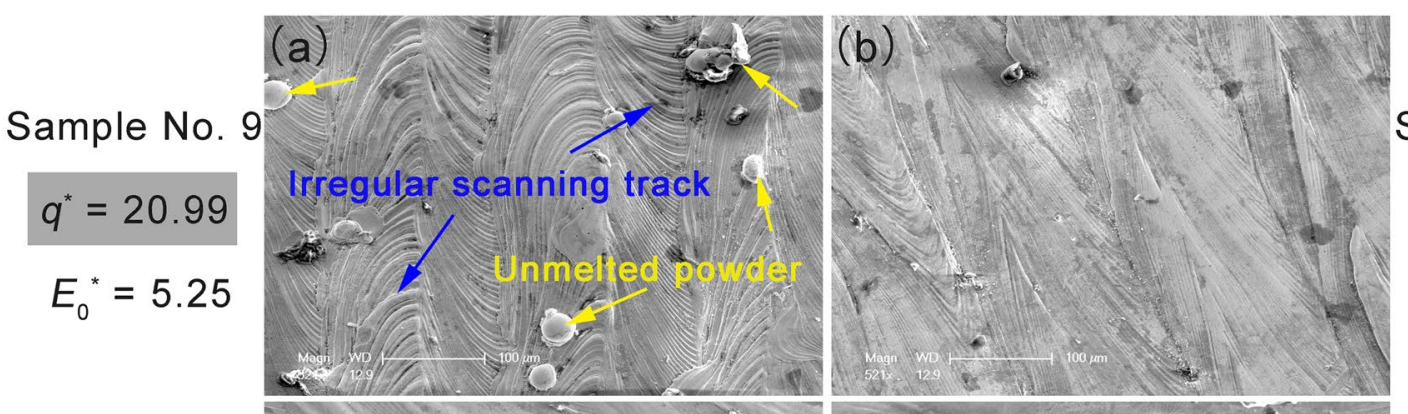

Sample No. 18

$$
\begin{aligned}
& q^{*}=45.52 \\
& E_{0}^{*}=5.25
\end{aligned}
$$

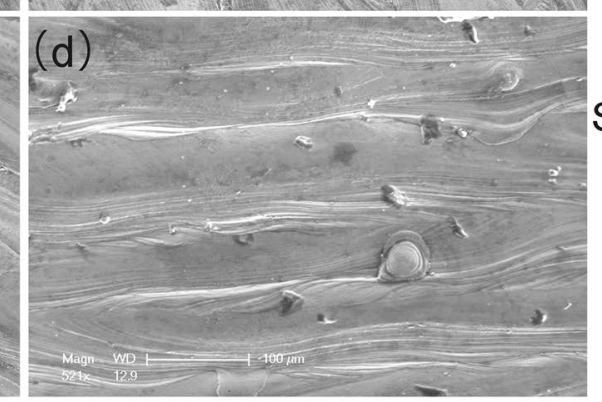

Sample No. 21

Sample No. 27

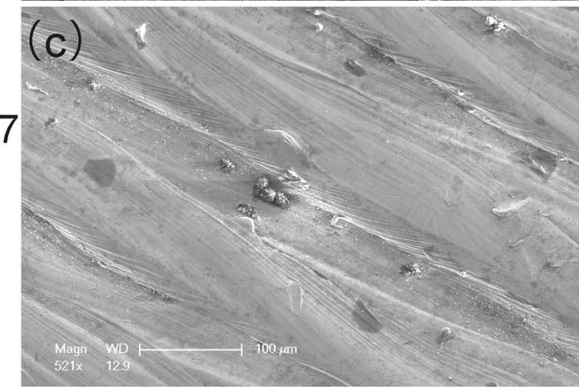

$q^{*}=79.54$

$q^{*}=79.54$

$E_{0}^{*}=5.25$
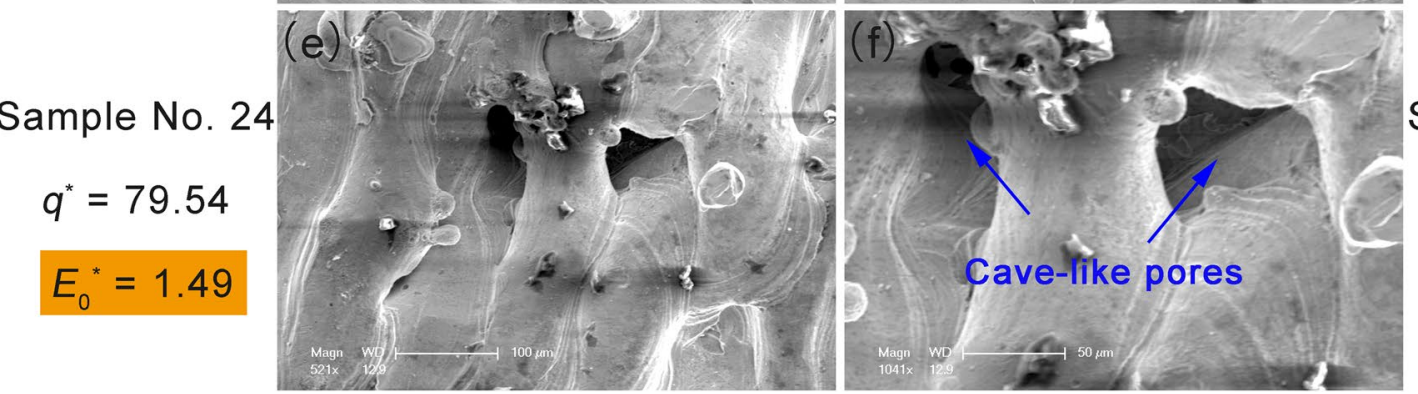

Sample No. 24

$q^{*}=79.54$

$$
E_{0}^{*}=1.49
$$

Fig. 6 SEM images showing the topography of the top surface structure of typical as-fabricated 316L SS samples: a-c effect of $q^{*}$ on the top surface structure when $E_{0} *$ is constant; $\mathbf{c}-\mathbf{e}$ effect of $E_{0}{ }^{*}$ on the top surface structure when $q^{*}$ is constant; $\mathbf{f}$ magnified view of $\mathbf{e}$ 


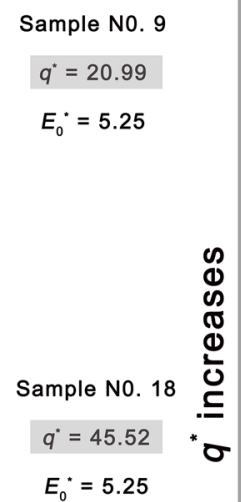

Sample N0. 27

$q^{*}=79.54$

$E_{0}{ }^{*}=5.25$
Sample N0. 21 $q^{*}=79.54$ $E_{0}{ }^{\circ}=2.33$

Sample N0. 24

$$
\begin{aligned}
& q^{*}=79.54 \\
& E_{0}{ }^{*}=1.49
\end{aligned}
$$
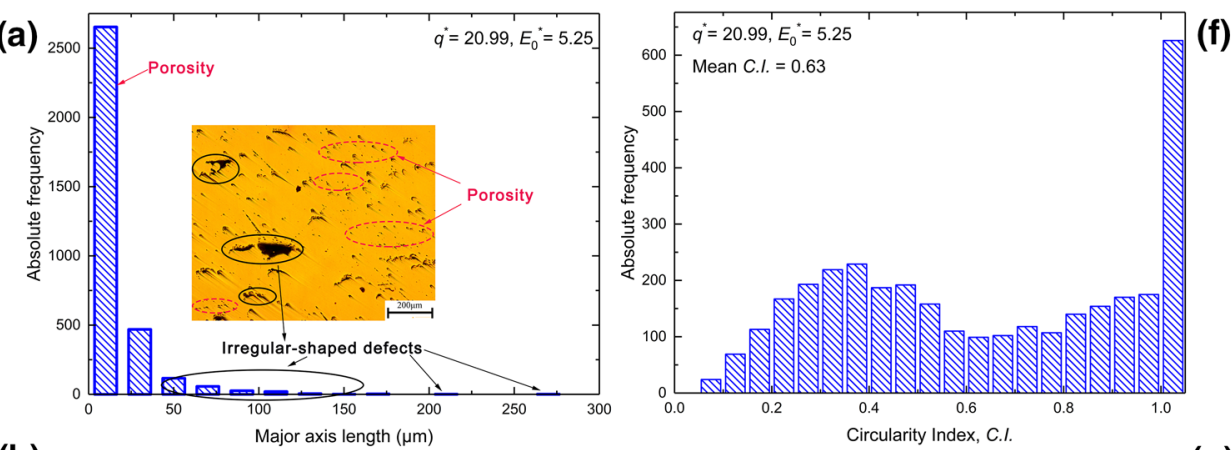

(f)
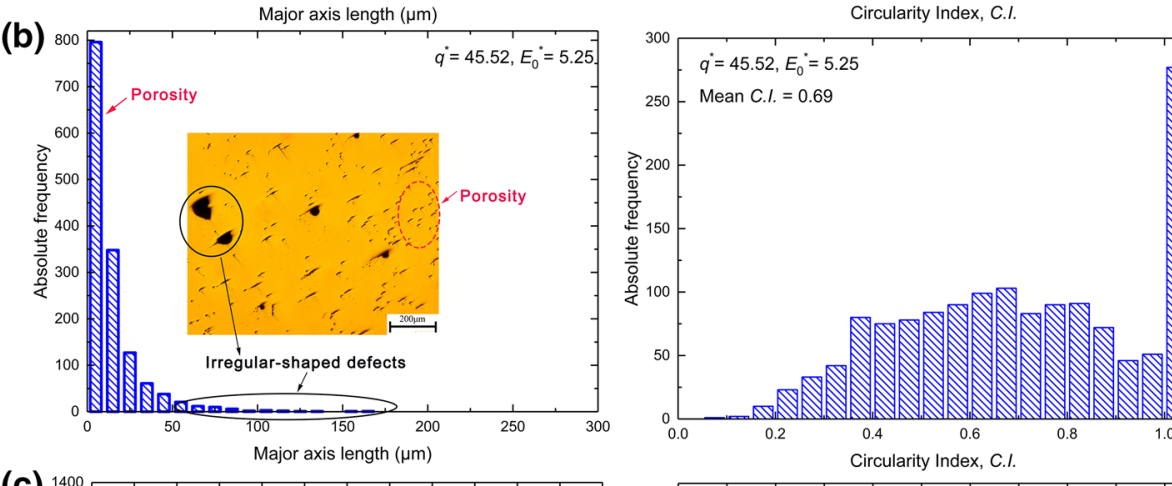

(g)

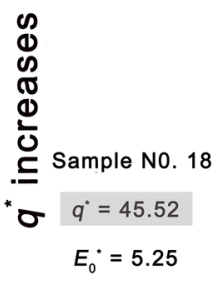

(h)
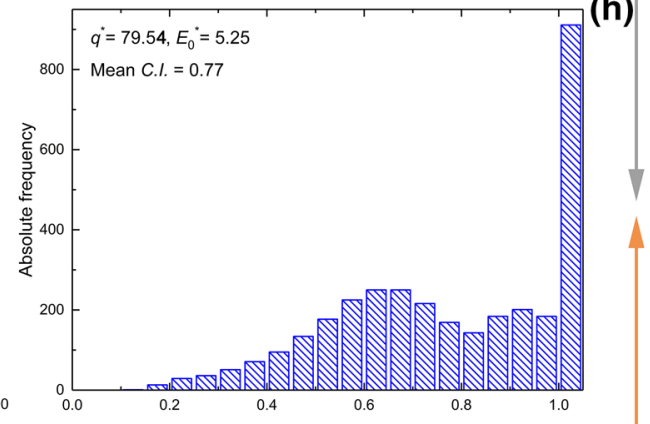

Sample N0. 27

$q^{*}=79.54$

$E_{0}{ }^{*}=5.25$

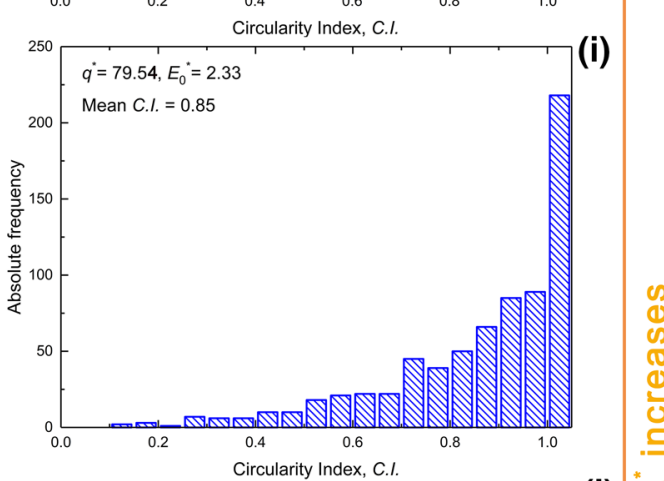

Sample N0. 21

$q^{*}=79.54$

$E_{0}^{*}=2.33$

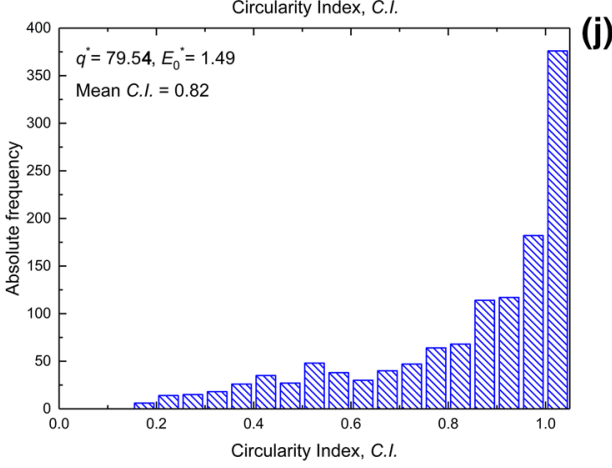

Sample N0. 9

$q^{*}=20.99$

$E_{0}{ }^{*}=5.25$
Sample NO. 24

$q^{*}=79.54$

$E_{0}{ }^{*}=1.49$ 
4Fig.7 Absolute frequency histograms illustrating the effect of process parameters on the size and morphology of defects: a-e defect size distributions $\mathbf{f}-\mathbf{j}$ morphology distributions

greater value of $E_{0} *$ (Figs. 5a and 6c, e). On the contrary, the density at the lowest $E_{0} *=1.49$ leads to a higher density $(98.60 \%)$ than that at the highest $E_{0} *=5.25(97.96 \%)$ (see Table 1). An investigation of the relationship between the relative density and melt pool shape will be discussed in detail in Sect. 3.1.3.

\subsubsection{Quantitative Statistics of Defect Size and Morphology}

The laser power used by earlier studies for the SLM process is usually less than $200 \mathrm{~W}$ [1, 3, 20]. Internal defects inadvertently become the focus of research. Currently, SLM machines with laser power greater than or equal to $400 \mathrm{~W}$ are increasingly becoming popular; few studies have been conducted using operating laser power greater than or equal to $400 \mathrm{~W}$ [9, 21, 34]. This could be because keyhole effect or intensive flows within the melt pool would be easily generated resulting in more internal defects [24, 35, 36]. Internal defects, such as lack of fusion, gas porosity, and keyhole mode pores, have great influence on the relative density and mechanical performance of SLM-produced parts. Figure 7 depicts the absolute frequency histograms of the number of defects detected across a constant area of analysis of $\sim 7.5 \mathrm{~mm}^{2}$. It shows that the size and morphology of defects vary with $E_{0} *$ and $q^{*}$. The size of defects can be classified into two types: one is irregular defect, which is usually greater than $50 \mu \mathrm{m}$ (i.e., large defect), and the other is small pore, which is less than $50 \mu \mathrm{m}$. It is observed that the absolute frequency of large defects reduces from 161 to 32 with increasing $q^{*}$ when $E_{0} *$ remains at 5.25 (Fig. $7 \mathrm{a}-\mathrm{c}$ and Table 3). Irregular defects, which are caused by lack of fusion, are mainly attributed to insufficient melting of powder or a small penetration depth [37], and can be reduced by importing enough heat into powder bed. At a constant $E_{0} *$ (i.e., $E_{0} *=5.25$ ), the temperature rising at $\mathrm{H}-\mathrm{P}$ is higher than those at M-P and L-P, which leads to a more complete melting process; thus, irregular defects caused by lack of fusion decrease with increasing laser power (see Electronic supplementary material). However, too much heat imported into Sample No. 27 leads the maximum temperature in the melt pool to exceed the material boiling temperature, resulting in significant keyhole defects in the part (Fig. 7c, the inset figure shows that many small pores are formed, and Fig. 8). The absolute frequency of small pores detected in Sample No. 27 is 3308 (see Table 3), which is greater than that of other samples. At a constant $q^{*}$ (i.e., $q^{*}=79.54$ ), the absolute frequency of large defects firstly decreases with $E_{0}{ }^{*}$ increasing (from 46 in Sample No. 24 to 15 in Sample No. 21 ) and then shows an increasing trend (from 15 in Sample
Nos. 21-32 in Sample No. 27, see Table 3). The tendency is corresponding to the variation in relative density. The result suggests that an optimum processing window for achieving high density SLM-manufactured part exists. Utilizing a combination of process parameters that far beyond this region can increase the tendency of forming large defect even $E_{0} *$ is sufficiently high (see Table 3 ). Despite the defect size distribution, its morphology was also quantified according to Eq. (5). The average value of CI was estimated based on the defect size morphology distribution (Fig. $7 \mathrm{f}-\mathrm{j}$ ). It is evident that when the $E_{0} *$ value is constant, the average CI increases from 0.63 to 0.77 with increasing $q^{*}$ (Fig. $7 \mathrm{f}-\mathrm{h}$ ). This implies that the morphology of defect tends to be spherical as the laser power increases when $E_{0} *$ is constant. The maximum $\mathrm{CI}=0.85$ corresponds to the highest density of $99.22 \%$ at $E_{0} *=2.33$ and $q^{*}=79.54$ (Fig. 7i). The quantitative statistics of defect size and morphology indicate that the morphology of defect is nearly spherical when high-density $(\geq 99 \%)$ parts are achieved.

\subsubsection{Melt Pool Shape}

It has been reported that the melt pool shape at high laser power is different from that at low laser power [9, 21]. A tensile sample with a narrow, deep melt pool shape would demonstrate better mechanical properties than that with a wide, shallow melt pool shape [9]. To reveal the locations of defects in melt pools and evaluate the melt pool shape variation with the process parameters, nine typical OM images of cross-sectional views of scanning tracks were arrayed on a rectangular plane coordinate with $q^{*}$ and $E_{0} *$ as the abscissa and ordinate, respectively. Generally, the melt pool shape has a small depth and long width at L-P, while it has a large depth and narrow width at H-P (Fig. 8). It has been pointed out that increasing melt pool depth is beneficial for enhancing the density of the built part [37]. It is observed that the melt pool depth becomes larger with the increase of $q^{*}$ when $E_{0} *$ is constant, and hence a higher relative density is achieved (Figs. 5a, 8). At a constant $q^{*}$, the melt pool depth shows an increasing trend with increasing $E_{0} *$. However, a large melt pool depth does not always bring a positive result. Significant keyhole defects are found on Sample No. 18 and No. 27, which correspond to relative densities of $97.37 \%$ and $97.96 \%$, respectively, lowering the density of the parts owing to melt pool instability. Furthermore, it is observed that the keyhole defects are usually located at the bottom of the melt pool and are spherical (Fig. 8, Sample No. 18 and No. 27), which is consistent with the experimental result of King et al. [24]. The experimental results showed that the melt pool shape could be tailored by the SLM process parameters and a relative density $>98.5 \%$ could be achieved at a lower $E_{0}$ *. 
Table 3 Absolute frequency of large defects and the total absolute frequency of defects detected at different samples

\begin{tabular}{llllll}
\hline Sample & $\begin{array}{l}\text { No. 9 (L-P, } \\
\left.E_{0}{ }^{*}=5.25\right)\end{array}$ & $\begin{array}{l}\text { No. 18 (M-P, } \\
\left.E_{0}^{*}=5.25\right)\end{array}$ & $\begin{array}{l}\text { No. 27 (H-P, } \\
\left.E_{0}^{*}=5.25\right)\end{array}$ & $\begin{array}{l}\text { No. 21 (H-P, } \\
\left.E_{0}{ }^{*}=2.33\right)\end{array}$ & $\begin{array}{l}\text { No. 24 } \\
\text { (H-P, } \\
\left.E_{0}^{*}=1.49\right)\end{array}$ \\
\hline $\begin{array}{c}\text { Absolute } \\
\text { frequency of } \\
\text { large defects } \\
(>50 \mu \mathrm{m})\end{array}$ & 161 & 60 & 32 & 15 & 46 \\
$\begin{array}{c}\text { Total absolute } \\
\text { frequency of } \\
\text { defects }\end{array}$ & 3352 & 1430 & 3340 & 720 & 1265 \\
\hline
\end{tabular}

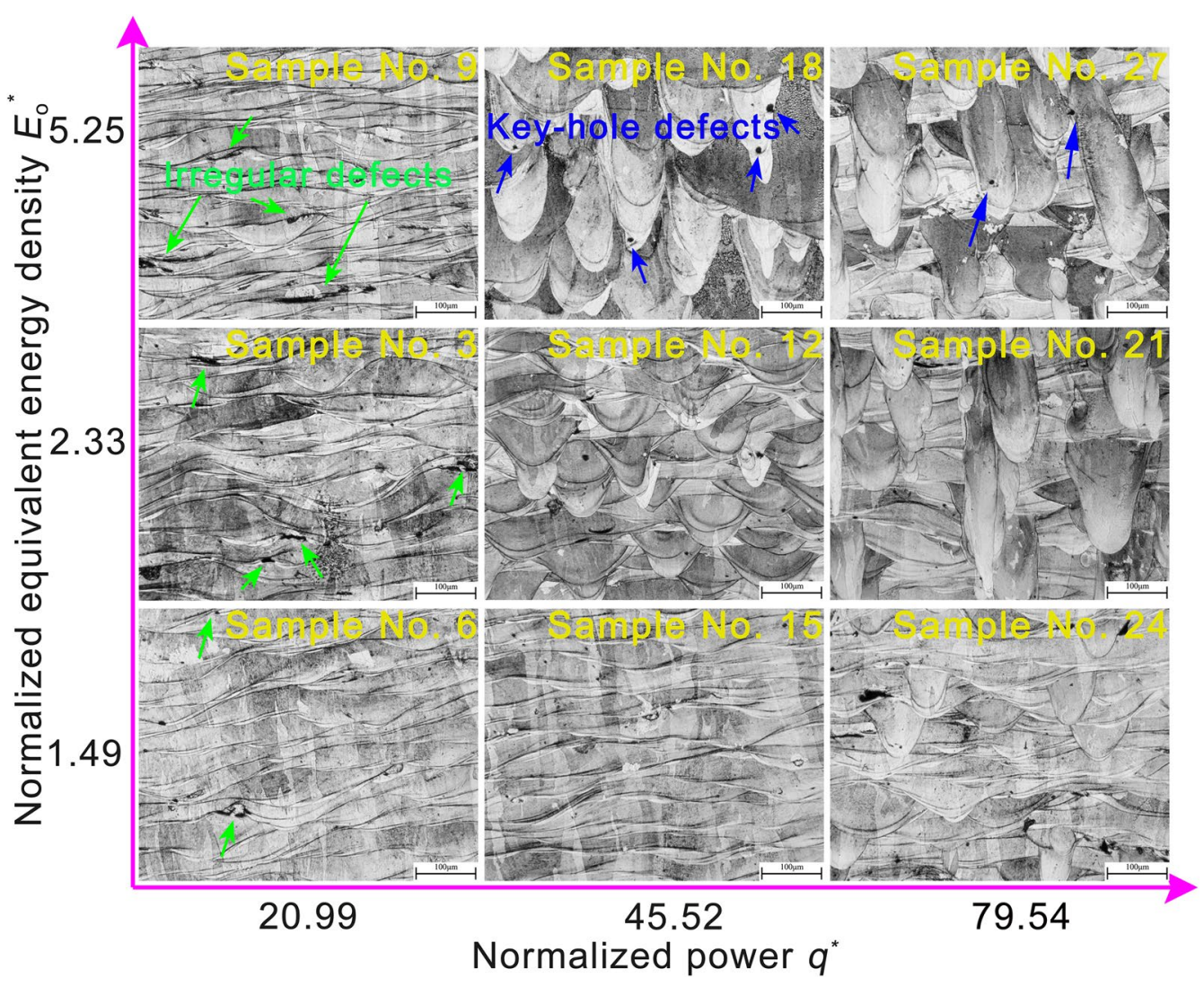

Fig. 8 Nine OM images of cross-sectional views of scanning tracks with $q^{*}$ and $E_{0} *$ as abscissa and ordinate, respectively (the dark blue arrows indicate keyhole defects, while the green ones represent irregular defects)

Figure 8 indicates that periodic melt pools experience partial overlapping and remelting. The laser scanning direction is rotated by $67^{\circ}$ layer by layer, leading to deviations in the orientation of the melt pools. It is observed that irregular defects are more likely to occur at L-P than at M-P and H-P, and these defects are usually located at the bottom of the melt pool boundaries (Fig. 8, Sample No. 3, No. 6, and No. 9). These irregular defects are detrimental to the relative density and in turn affect the mechanical properties of parts. It is noteworthy that irregular defects are also observed at a greater $E_{0}{ }^{*}$ using L-P (Fig. 8, Sample No. 9). One of the possible reasons is that the stability zone at L-P is relatively narrower than that at $\mathrm{H}-\mathrm{P}$ when $E_{0} *$ remains at 5.25. Such a high-energy density $\left(E_{0}^{*}=5.25\right)$ at L-P is beyond the optimum processing window for forming a single track [38]. Thus, a non-continuous single track containing many irregular defects is formed. On the other hand, a high $E_{0} *$ leads to an increase in the single melt volume and a decrease in the melt viscosity. The melt hydrodynamics driven by the Marangoni effect become more significant in this case, both of which significantly affect the melt pool stability [38]. 


\subsection{Effect of Process Parameters on Primary Dendrite Spacing}

A hierarchical structure is now regarded as one of the main factors for simultaneously improving both strength and ductility of SLM-manufactured 316L SS parts [3, 10, 39]. It can be divided into multiple-length scales, e.g., macroscale level, microscale level, and nanoscale level. The typical structures of these characteristic length scales include melt pools generated by laser scanning, intragranular cellular segregation network structures (cellular structures in short), and oxide nano-inclusions formed in situ, respectively [3]. Figure 9a displays an SEM image parallel to the building direction
(Sample No. 6), which reveals the complex microstructure of the as-fabricated sample. The fusion boundaries, grain orientations (i.e., the longitudinal side and transverse region as indicated in Fig. 9a), and cellular structures (Fig. 9b) are clearly shown. By using the "area method," the primary dendrite spacing $\lambda_{0}$ can be calculated by the following equation [40]:

$\lambda_{0}=\frac{1}{M}\left(\frac{A_{0}}{N}\right)$,

where $M$ is the magnification of the SEM micrograph, $N$ is the number of the dendrites on the target zone indicated
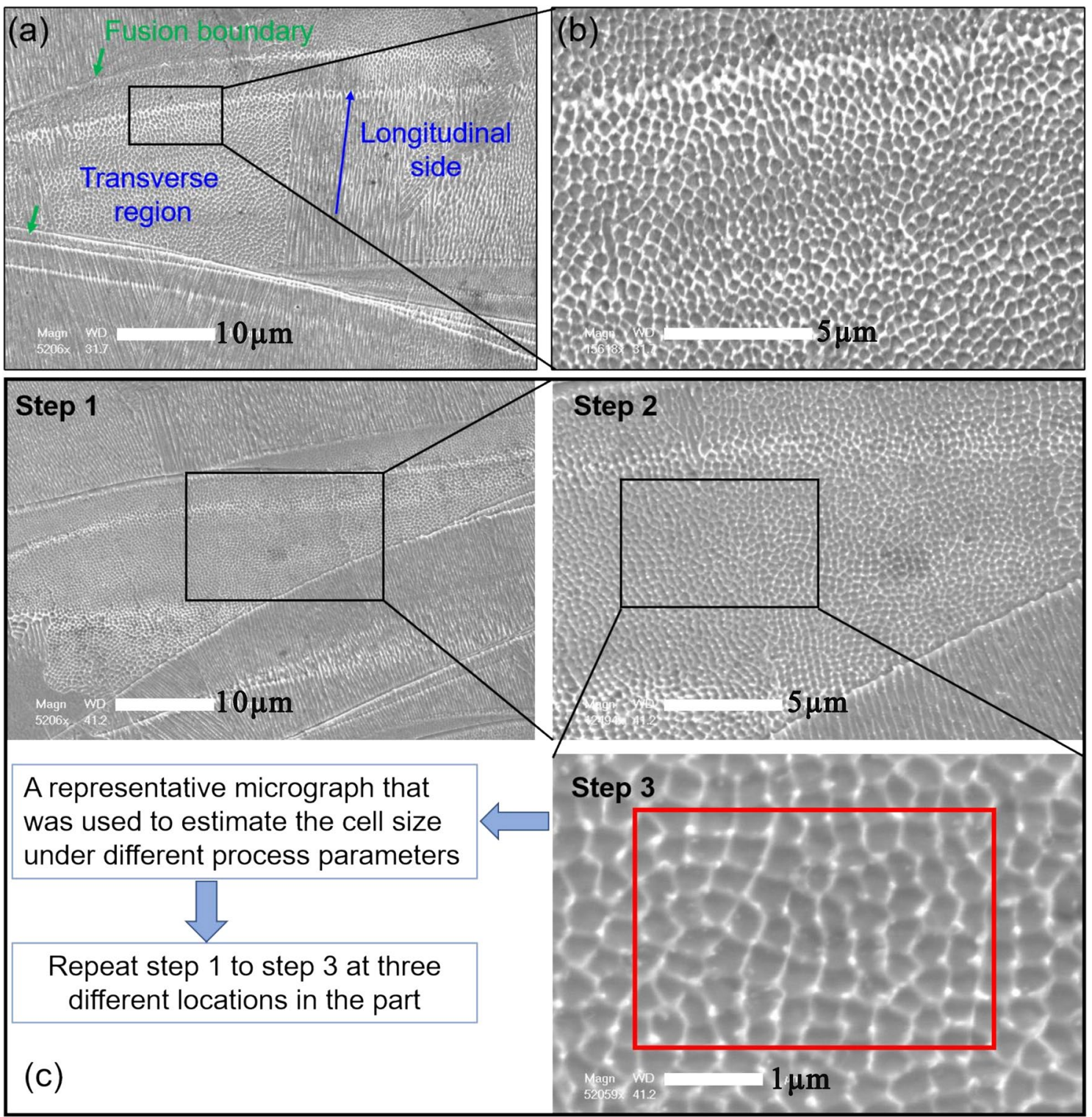

Fig. 9 a Typical SEM image of the as-fabricated sample revealing the complex microstructure of 316L SS sample, b magnified view revealing the solidified cellular structures in $\mathbf{a}$, $\mathbf{c}$ an example of conducting the SEM observations to measure the cell structure size at various process parameters 


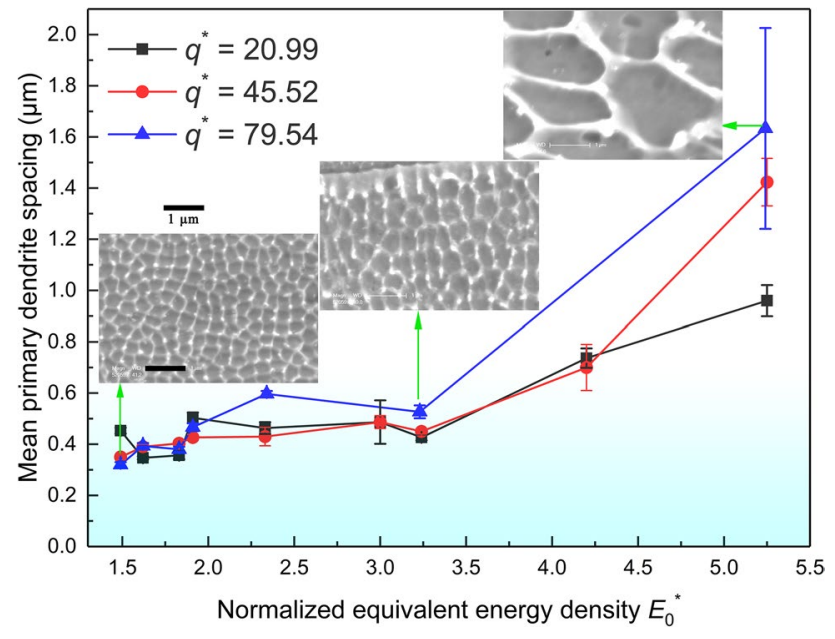

Fig. 10 Effect of process parameters on primary dendrite spacing (cell size)

by the red rectangle as shown in Figs. 9c, and $A_{0}$ is the area of the rectangle. The detailed procedures of conducting the SEM observations to measure the primary dendrite spacing are illustrated in Fig. 9c. Figure 10 shows that the primary dendrite spacing monotonously increases from $\sim 0.35$ to $\sim 1.5 \mu \mathrm{m}$ when $E_{0} *$ increases from 1.49 to 5.25 . The difference in the primary dendrite spacing at a constant $E_{0}{ }^{*}$ becomes more divergent, especially when $E_{0} *$ is greater than 3.24 , while the difference is little when $E_{0} *$ increases from 1.91 to 3.24 . The result indicates that an optimum processing window exists in this range because a refined primary dendrite spacing (Fig. 10) and a relative density $>98.5 \%$ (Fig. 5a) are achieved simultaneously.

It is known that primary dendrite spacing is dependent on the cooling rate. For SLM-produced 316L SS, it is expressed as follows [41]:

$\lambda_{0}=80 \dot{T}^{-0.33}$,

where $\dot{T}(\mathrm{~K} / \mathrm{s})$ is the cooling rate, which is $\dot{T}=\left(\lambda_{0} / 80\right)^{-3}$. According to Zhong et al. [3], when low scanning speed is utilized, i.e., a higher energy density, the resulted lower cooling rate will lead to larger micro-sized cells as the size of the cellular structure depends on the cooling rate. Figure 11 depicts the calculated cooling rate under various process parameters in this study. It is evident that a higher cooling rate is achieved at a lower $E_{0}{ }^{*}$, and the cooling rate shows a decreasing trend when the overall energy density imported to the powder bed increased. The cooling rate in our experiment ranges from the order of $10^{5}-10^{7} \mathrm{~K} / \mathrm{s}$, which is consistent with that of other studies [3, 4, 21]. From Fig. 10 and Fig. 11, it can be concluded that a lower $E_{0} *$ leads to a higher cooling rate, resulting in a finer microstructure. It is suggested that the yield strength $\sigma_{y}$ of a SLM-manufacture

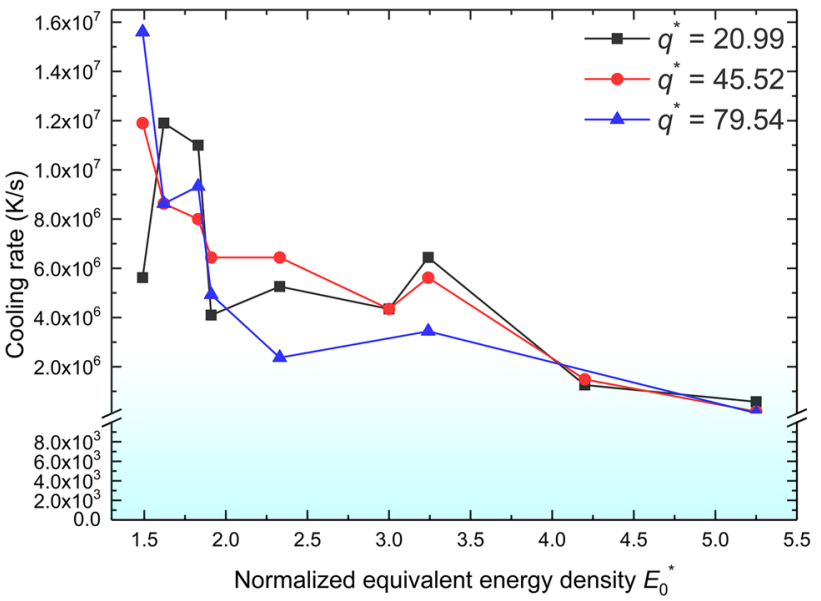

Fig. 11 Effect of process parameters on the cooling rate of the as-fabricated samples

part can be estimated by primary dendrite spacing $\lambda_{0}$ (i.e., cell size). The expression is [10]

$\sigma_{y}=183.31+253.66 /\left(\lambda_{0}\right)^{0.5}$.

Apparently, a higher YS results from a refined cellular structure, which can be obtained at a relatively lower $E_{0} *$. It is notable that the energy density utilized by concept [10] is approximately $E_{0} *=2.0$, which is far lower than the energy density used by most researchers $[9,11,39,42]$. Therefore, selecting a combination of process parameters that results in a low $E_{0}{ }^{*}$ will be of great importance for SLM-processed parts to attain good mechanical properties. However, an extremely low $E_{0} *$ is detrimental to the relative density of such parts [4, 39]. It should be pointed out that the cell size is only one of the strengthening mechanisms. Sun et al. [9] argued that a different melt pool shape results in a different crystallographic texture, which is also a strengthening mechanism, by affecting the deformation twinning capacity and amount of initial dislocation density. Therefore, reducing the effect of the melt pool shape on the mechanical property is of remarkable importance in terms of its cell size under different process parameters.

\subsection{Verification of Achieving Good Tensile Properties at Low $E_{0}^{*}$}

To achieve excellent mechanical properties by controlling microstructure of SLM-manufactured parts, the volume energy density has been widely adopted by many researchers in designing or optimizing the process parameters of SLM-manufactured parts [33, 27, 39, 43]. However, the value is close to $104.52 \mathrm{~J} / \mathrm{mm}^{3}$ in Refs. [9, 33, 27] and is approximately $69 \mathrm{~J} / \mathrm{mm}^{3}$ in Ref. [10]. Notice that the tensile 
behavior of the sample with $69 \mathrm{~J} / \mathrm{mm}^{3}$ is better than many reported data so far. Based on the experimental results shown in Figs. 10 and 11, it can be deduced that further improving the strength of a SLM-manufactured part via a low $E_{0} *$ might be one of the feasible ways to achieve this goal. To evaluate the above results of relative density, melt pool shape, and primary dendrite spacing, two sets of tensile tests were performed. The principles of parameter selection from Table 1 are as follows:

1. The density of the built part is larger than $98.5 \%$.

2. The cell size is less than $0.5 \mu \mathrm{m}$.

3. The melt pool should not be too deep, and the melt tracks should be well overlapped by adjacent ones.

4. The corresponding $E_{0} *$ is relatively low.

Therefore, the parameters corresponding to Sample No. 12 and No. 24 were selected and dogbone samples were produced using these parameters. The normalized work hardening rate is calculated as $\theta^{\prime}=(\mathrm{d} \sigma / \mathrm{d} \varepsilon) / G$, where $\sigma$ and $\varepsilon$ are the true stress and true strain, respectively, and $G$ is the shear modulus for 316L SS [9]. For convenience, the tensile test results are simply expressed for Sample No. 12 $\left(q^{*}=45.52\right.$ and $\left.E_{0}^{*}=2.33\right)$ and Sample No. $24\left(q^{*}=79.54\right.$ and $E_{0} *=1.49$ ) on the following.

Figure 12a, b illustrates the engineering tensile stress-strain curves and true stress-strain curves for the two sets of process parameters, respectively. A uniform elongation is highlighted in Fig. 12a. The representative normalized work hardening rates as a function of the true strain are presented in Fig. 12c. It can be observed that the two sets of process parameters resulted in excellent mechanical properties when compared with many research works (Electronic supplementary material). The mechanical properties of Sample No. 12 (YS = $584 \mathrm{MPa}$, ultimate tensile strength $($ UTS $)=773 \mathrm{MPa}$, and elongation to failure $\left.\left(\varepsilon_{\mathrm{f}}\right)=46 \%\right)$ are better than those of Sample No. 24 (YS $=549 \mathrm{MPa}$,

(b)
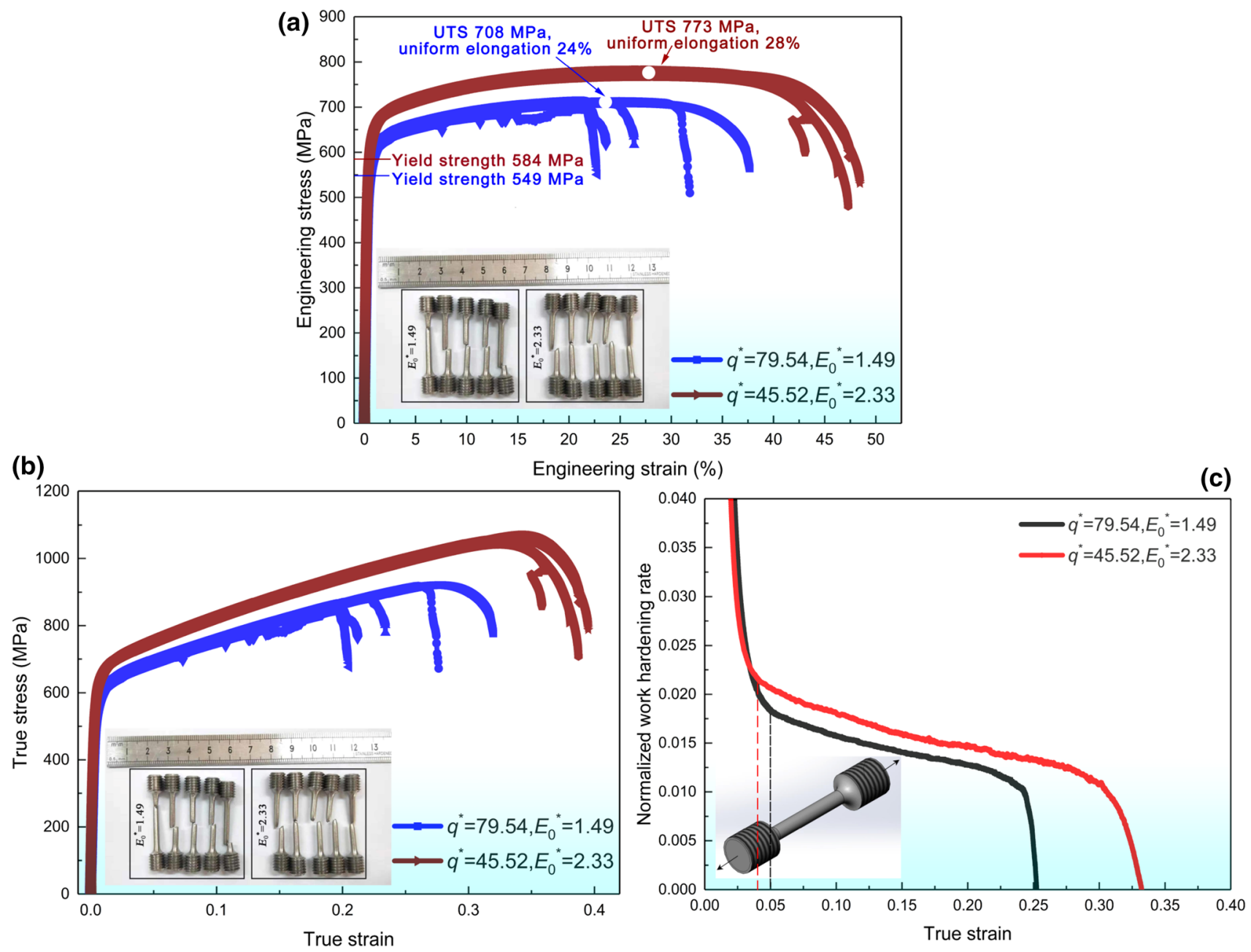

Fig. 12 Tensile properties of SLM-processed 316L SS: a engineering tensile stress-strain curves; b true stress-strain curves; $\mathbf{c}$ representative normalized work hardening rate curves as a function of true strain in the two process parameters 
$\mathrm{UTS}=708 \mathrm{MPa}$, and $\varepsilon_{\mathrm{f}}=28 \%$ ). The work hardening period of Sample No. 12, which started at a true strain of $\sim 0.04$, is longer than that of Sample No. 24 (true strain of $\sim 0.05$ ) (Fig. 12c). This is a common phenomenon for SLM-processed parts with high ductility [9, 10]. Moreover, the stress-strain curves of Sample No. 12 show good consistency, while that of Sample No. 24 shows a larger dispersion. Since the relative density of Sample No. 12 (98.93\%) is greater than that of Sample No. 24 (98.6\%) (Fig. 5a), it can be deduced that the defects in Sample No. 24, which are located at the melt pool boundaries or columnar grain boundaries, are greater in number than those of Sample No. 12. These defects become the weakest region and the starting point of failure [3]. In addition, the defect morphology of Sample No. 24 tends to be irregular in shape compared with that of Sample No. 12 (Fig. 8). SEM fractographs of fracture surfaces also show that there are many irregular defects on Sample No. 24 (Fig. 13a), while relatively fewer spherical pores with defect size $<50 \mu \mathrm{m}$ are observed on Sample No. 12 (Fig. 13d), which agree with the aforementioned results. Moreover, a ductile fracture mode with typical submicronsized dimples is more likely to occur for Sample No. 12 (Figs. 13e, 14f), while more brittle fracture features with pulling out of "melt pools" are more likely to occur for Sample No. 24 (Figs. 13b, 14c). The results imply that improving the density of SLM-processed parts at relatively low $E_{0}{ }^{*}$ will lead to more submicron-sized dimples; thus, ductility can be significantly enhanced. As shown in Fig. 10, the average cell sizes of Sample No. 24 and Sample No. 12 are $0.32 \mu \mathrm{m}$ and $0.43 \mu \mathrm{m}$, respectively. The YS values for Sample No. 24 and Sample No. 12 calculated using Eq. (8) are $632 \mathrm{MPa}$ and $570 \mathrm{MPa}$, respectively. The latter agrees reasonably with the experiment result (584 MPa). However, the former significantly differs from the experiment result (549 $\mathrm{MPa}$ ), indicating that pore number and defect morphology are also of great influence to the accuracy of estimation when Eq. (8) is utilized to estimate yield strength of a SLM-manufactured part. Large irregular defects in Sample No. 24 lead to earlier necking, thereby sacrificing both strength and ductility. The results illustrate that mechanical properties of SLMmanufactured parts can be enhanced via a low $E_{0} *$ (i.e., $\left.E_{0} *=2.33\right)$. Further eliminating porosity at a much lower $E_{0} *$ is a major challenge to improve the material properties.

Finally, it is noteworthy that very high UTS values (>700 MPa) are obtained by the two sets of selected process parameters. Figure 14 depicts the tensile test results for SLM-manufactured 316L SS including ours and that of conventionally made steel. The mechanical properties of the as-fabricated samples by Fraunhofer [10] are not included because the spot diameter of the machine is $207 \mu \mathrm{m}$, which is substantially greater than that of the general SLM machine. As shown in Fig. 14, the SLM-manufactured 316L SS parts at a low $E_{0} *$ (i.e., $E_{0} *=2.33$ ) in this study generally show a higher strength and elongation to failure than conventionally manufactured parts. The UTS at $E_{0} *=2.33$ surpasses many reported values in the literature, and a better $\varepsilon_{\mathrm{f}}$ is also obtained. Increasing $E_{0}{ }^{*}$ at a relatively low level (e.g., from $E_{0}{ }^{*}=1.49$ to $E_{0} *=2.33$ ) will significantly improve the YS, UTS, and $\varepsilon_{\mathrm{f}}$ (Fig. 12a). Although there are many irregular defects in Sample No. 24, a very high UTS (708 MPa) is also achieved. The above results strongly suggest that utilizing a
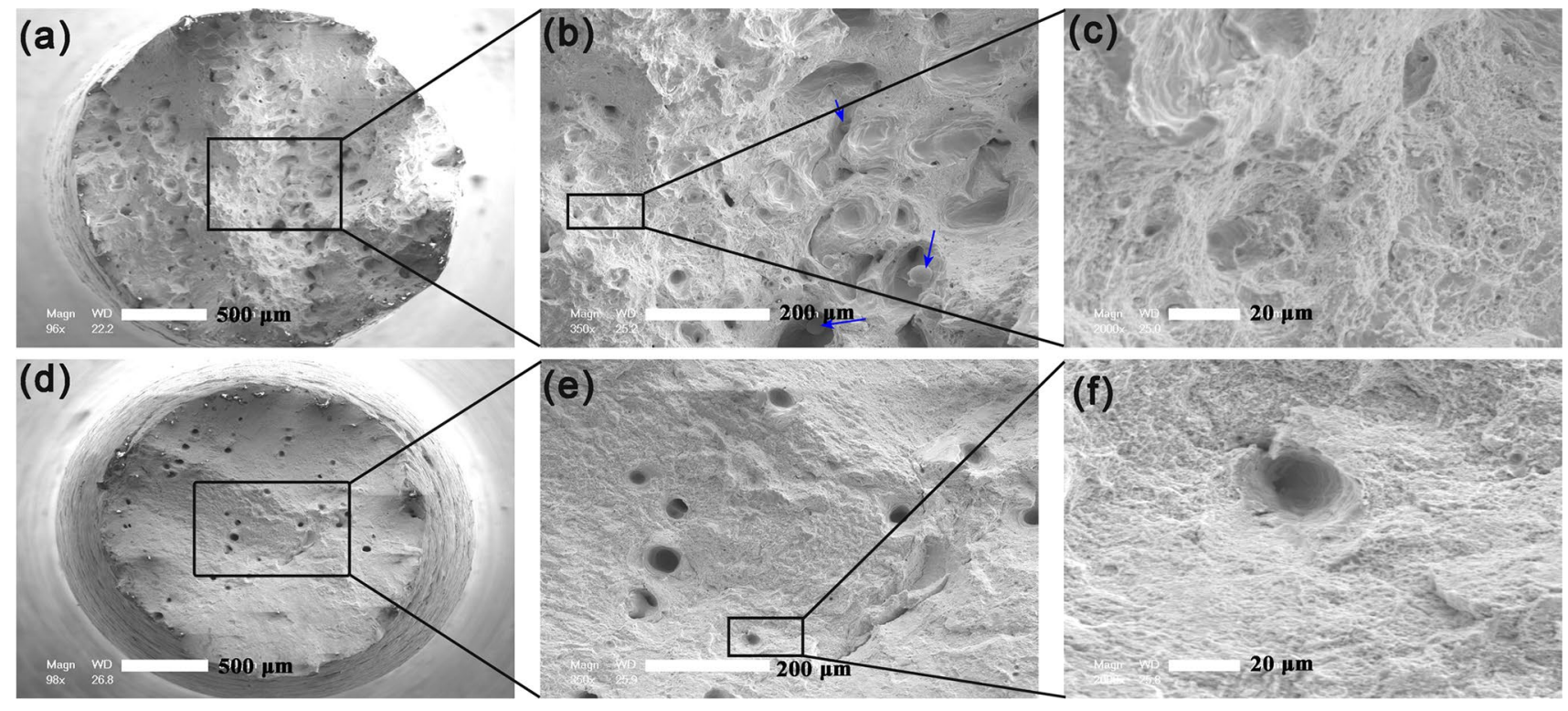

Fig. 13 SEM fractographs of the as-fabricated tensile specimens at different values of energy density: a-c Sample No. $24\left(q^{*}=79.54\right.$ and $\left.E_{0} *=1.49\right)$ with unmelted spherical powder granules marked by blue arrows; $\mathbf{d}-\mathbf{f}$ Sample No. $12\left(q^{*}=45.52\right.$ and $\left.E_{0} *=2.33\right)$ 


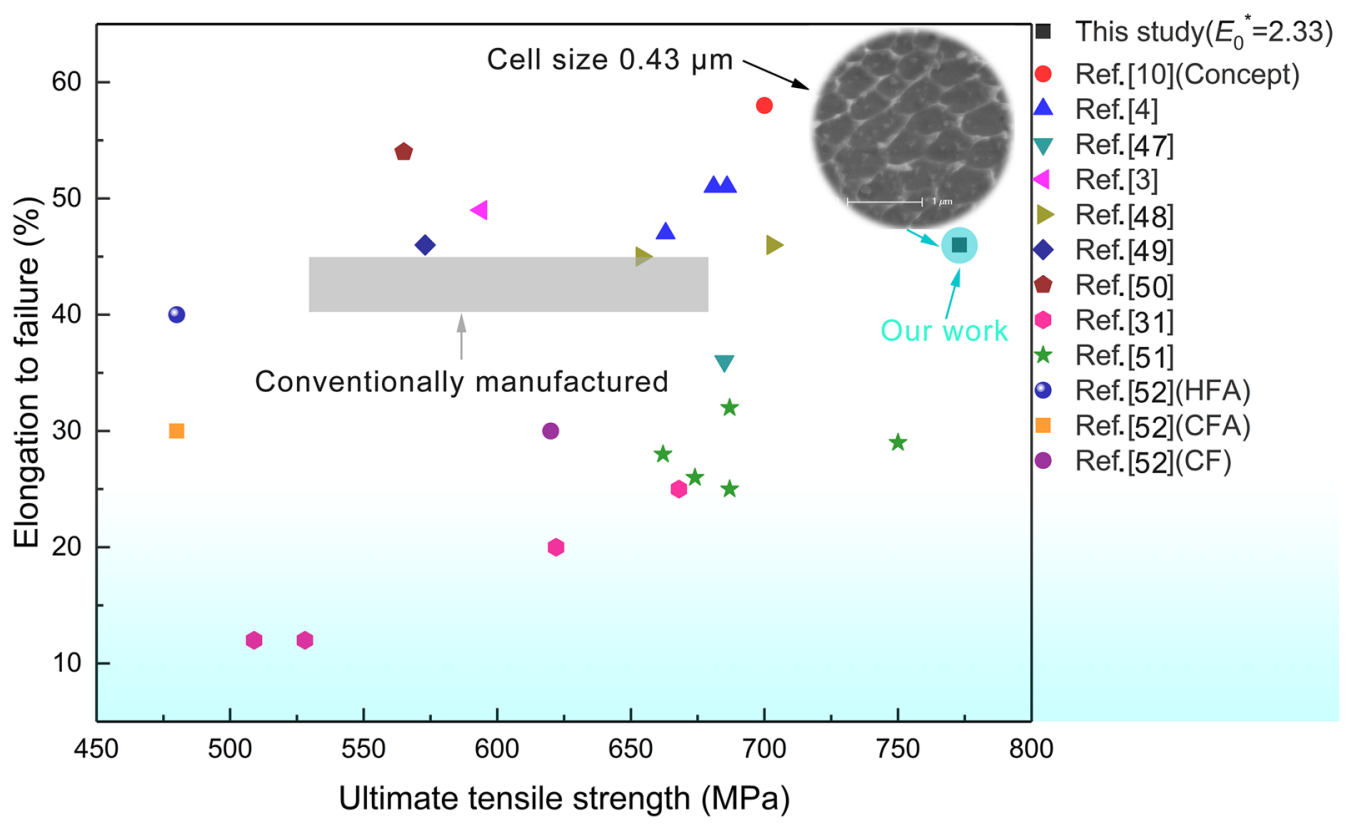

Fig. 14 Summary of ultimate tensile strength versus elongation to failure for 316L SS from our work and previous studies (the mechanical performance range of conventional wrought $316 \mathrm{~L}$ SS is shown in the block region; HFA—hot finished + annealed; CFA—cold finished + annealed; $\mathrm{CF}$ - cold finished)

combination of process parameters that result in relatively low $E_{0} *$ is very helpful to mechanical enhancement.

\section{Conclusions}

By deliberately designing a group of dimensionless variables and a normalized process map, a comprehensive investigation on the resulting defects, melt pool shapes, and microstructures of SLM-processed 316L SS parts was carried out. Excellent tensile properties of the built samples were achieved without heat treatment. It was confirmed that the refined intragranular cellular structure was responsible for the excellent properties although other strengthening mechanisms remain to be revealed. The following conclusions can be drawn:

1. The density of the parts at high power is generally greater than those at low power and medium power when $E_{0} *$ is constant. The highest density range is associated with $E_{0} *$ and $q^{*}$ values of approximately $1.83-2.33$ and $45.52-79.54$, respectively.

2. The maximum temperature rising in the SLM process plays an important role in the formation of large defects. The number of large defects decreases with an increasing $E_{0} *$ but increases if $E_{0} *$ exceeds 2.33 , corresponding to the variation in density. The morphology of the defect is nearly spherical when high-density $(\geq 99 \%)$ parts are achieved.
3. The cooling rate tends to monotonously decrease with increasing $E_{0} *$ and ranges in the order of $10^{5}-10^{7} \mathrm{~K} / \mathrm{s}$, while the primary dendrite spacing monotonously increases from $\sim 0.35$ to $\sim 1.5 \mu \mathrm{m}$ when $E_{0} *$ increases from 1.49 to 5.25 .

4. Excellent properties, namely $\mathrm{YS}=584 \mathrm{MPa}$, $\mathrm{UTS}=773 \mathrm{MPa}$, and $\varepsilon_{\mathrm{f}}=46 \%$, are achieved at a relatively low $E_{0} *$ with a relative density of $\sim 99 \%$, cell size of $\sim 0.43 \mu \mathrm{m}$, and without heat treatment, which greatly surpass those of conventionally fabricated parts.

Acknowledgements This work has been supported by the National Natural Science Foundation of China (Grant No. 11772344) and the National Key R\&D Program of China (Project No. 2016YFB1100700). The authors would like to thank PhD candidate, Yan-Sen Li, for the experimental assistance concerning scanning electron microscopy.

\section{References}

[1] I. Yadroitsev, Dissertation (Central University of Technology, Free State, 2009)

[2] C. Yu, Y. Zhong, P. Zhang, Z. Zhang, C. Zhao, Z. Zhang, Z. Shen, W. Liu, Acta Metall. Sin. Engl. Lett. 33, 539 (2020)

[3] Y. Zhong, L.F. Liu, S. Wikman, D.Q. Cui, Z.J. Shen, J. Nucl. Mater. 470, 170 (2016)

[4] C. Qiu, M. Al Kindi, A.S. Aladawi, I. Al Hatmi, Sci. Rep. 8, 7785 (2018)

[5] L.Z. Wang, W.H. Wei, Acta Metall. Sin. Engl. Lett. 31, 807 (2018)

[6] J.H. Martin, B.D. Yahata, J.M. Hundley, J.A. Mayer, T.A. Schaedler, T.M. Pollock, Nature 549, 365 (2017) 
[7] D. Zhang, D. Qiu, M.A. Gibson, Y. Zheng, H.L. Fraser, D.H. StJohn, M.A. Easton, Nature 576, 91 (2019)

[8] M. Shamsujjoha, S.R. Agnew, J.M. Fitz-Gerald, W.R. Moore, T.A. Newman, Metall. Mater. Trans. A 49, 3011 (2018)

[9] Z.J. Sun, X.P. Tan, S.B. Tor, C.K. Chua, NPG. Asia Mater. 10, $127(2018)$

[10] Y.M. Wang, T. Voisin, J.T. McKeown, J. Ye, N.P. Calta, Z. Li, Z. Zeng, Y. Zhang, W. Chen, T.T. Roehling, R.T. Ott, M.K. Santala, P.J. Depond, M.J. Matthews, A.V. Hamza, T. Zhu, Nat. Mater. 17, 63 (2018)

[11] L. Liu, Q. Ding, Y. Zhong, J. Zou, J. Wu, Y.L. Chiu, J. Li, Z. Zhang, Q. Yu, Z. Shen, Mater. Today 21, 354 (2018)

[12] W. Yang, Y. Tarng, J. Mater. Process. Technol. 84, 122 (1998)

[13] T. Mukherjee, V. Manvatkar, A. De, T. DebRoy, J. Appl. Phys. 121, 064904 (2017)

[14] J.C. Ion, H.R. Shercliff, M.F. Ashby, Acta Metall. Mater. 40, 1539 (1992)

[15] M. Thomas, G.J. Baxter, I. Todd, Acta Mater. 108, 26 (2016)

[16] H.Z. Jiang, Z.Y. Li, T. Feng, P.Y. Wu, Q.S. Chen, Y.L. Fen, S.W. Li, H. Gao, H.J. Xu, Opt. Laser. Technol. 119, 105592 (2019)

[17] K. Darvish, Z.W. Chen, T. Pasang, Mater. Des. 112, 357 (2016)

[18] Z. Li, T. Voisin, J.T. McKeown, J.C. Ye, T. Braun, C. Kamath, W.E. King, Y.M. Wang, Int. J. Plast. 120, 395 (2019)

[19] H. Hou, E. Simsek, T. Ma, N.S. Johnson, S. Qian, C. Cissé, D. Stasak, N. Al Hasan, L. Zhou, Y. Hwang, Science 366, 1116 (2019)

[20] E.O. Olakanmi, R.F. Cochrane, K.W. Dalgarno, J. Mater. Process. Technol. 211, 113 (2011)

[21] M. Ma, Z. Wang, X. Zeng, Mater. Sci. Eng. A 685, 265 (2017)

[22] S.A. Khairallah, A.T. Anderson, A. Rubenchik, W.E. King, Acta Mater. 108, 36 (2016)

[23] T. Debroy, H.L. Wei, J.S. Zuback, T. Mukherjee, J.W. Elmer, J.O. Milewski, A.M. Beese, A. Wilson-Heid, A. De, W. Zhang, Prog. Mater. Sci. 92, 112 (2018)

[24] W.E. King, H.D. Barth, V.M. Castillo, G.F. Gallegos, J.W. Gibbs, D.E. Hahn, C. Kamath, A.M. Rubenchik, J. Mater. Process. Technol. 214, 2915 (2014)

[25] C. Kamath, B. El-dasher, G.F. Gallegos, W.E. King, A. Sisto, Int. J. Adv. Manuf. Technol. 74, 65 (2014)

[26] A.B. Spierings, M. Schneider, R. Eggenberger, Rapid Prototyp. J. 17, $380(2011)$

[27] Z.J. Sun, X.P. Tan, S.B. Tor, W.Y. Yeong, Mater. Des. 104, 197 (2016)

[28] L. Thijs, F. Verhaeghe, T. Craeghs, J.V. Humbeeck, J.P. Kruth, Acta Mater. 58, 3303 (2010)

[29] J. Suryawanshi, K.G. Prashanth, U. Ramamurty, Mater. Sci. Eng. A 696, 113 (2017)

[30] C.L. Qiu, N.J.E. Adkins, M.M. Attallah, Acta Mater. 103, 382 (2016)

[31] Y.M. Wang, C. Kamath, T. Voisin, Z. Li, Rapid. Prototyp. J. 24, $1469(2018)$
[32] C.L. Qiu, C. Panwisawas, M. Ward, H.C. Basoalto, J.W. Brooks, M.M. Attallah, Acta Mater. 96, 72 (2015)

[33] J.A. Cherry, H.M. Davies, S. Mehmood, N.P. Lavery, S.G.R. Brown, J. Sienz, Int. J. Adv. Manuf. Technol. 76, 869 (2015)

[34] T. Niendorf, S. Leuders, A. Riemer, H.A. Richard, T. Tröster, D. Schwarze, Metall. Mater. Trans. B 44, 794 (2013)

[35] R. Cunningham, C. Zhao, N. Parab, C. Kantzos, J. Pauza, K. Fezzaa, T. Sun, A.D. Rollett, Science 363, 849 (2019)

[36] L. Cla, S. Marussi, R.C. Atwood, M. Towrie, P.J. Withers, P.D. Lee, Nat. Commun. 9, 1355 (2018)

[37] T. Mukherjee, J.S. Zuback, A. De, T. DebRoy, Sci. Rep. 6, 19717 (2016)

[38] I. Yadroitsev, P. Bertrand, I. Smurov, Appl. Surf. Sci. 253, 8064 (2007)

[39] D. Wang, C.H. Song, Y.Q. Yang, Y.C. Bai, Mater. Des. 100, 291 (2016)

[40] M. Ma, Z. Wang, G. Ming, X. Zeng, J. Mater. Process. Technol. 215, 142 (2015)

[41] S. Katayama, A. Matsunawa, in International Congress on Applications of Lasers \& Electro-Optics, vol. 44 (Laser Institute of America, New York, 1984), p. 60

[42] K. Saeidi, X. Gao, F. Lofaj, L. Kvetková, Z.J. Shen, J. Alloys Compd. 633, 463 (2015)

[43] A.T. Sidambe, Y. Tian, P.B. Prangnell, P. Fox, Int. J. Refract. Met. Hard Mat. 78, 254 (2019)

[44] D. Bäuerle, Laser Processing and Chemistry, 4th edn. (Springer, Berlin, 2011)

[45] R. Casati, J. Lemke, M. Vedani, J. Mater. Sci. Technol. 32, 738 (2016)

[46] K. Saeidi, L. Kvetkova, F. Lofajc, Z.J. Shen, RSC Adv. 5, 20747 (2015)

[47] C. Elangeswaran, A. Cutolo, G.K. Muralidharan, C. de Formanoir, F. Berto, K. Vanmeensel, B. Van Hooreweder, Int. J. Fatigue 123, 31 (2019)

[48] A. Riemer, S. Leuders, M. Thöne, H. Richard, T. Tröster, T. Niendorf, Eng. Fract. Mech. 120, 15 (2014)

[49] T. Kurzynowski, K. Gruber, W. Stopyra, B. Kuźnicka, E. Chlebus, Mater. Sci. Eng. A 718, 64 (2018)

[50] ASM International Handbook Committee, ed. by S.D. Washko and G. Aggen. Properties and Selection: Irons, Steels, and HighPerformance Alloys, vol. 1, 10th Edition (USA, 1990), p. 2049

[51] K. Saeidi, X. Gao, Y. Zhong, Z.J. Shen, Mater. Sci. Eng. A 625, 221 (2015)

[52] T. Voisin, N.P. Calta, S.A. Khairallah, J.B. Forien, L. Balogh, R.W. Cunningham, A.D. Rollett, Y.M. Wang, Mater. Des. 158, $113(2018)$ 